\title{
ACCESO TRANSNACIONAL A LA JUSTICIA Y GOBERNANZA GLOBAL (COMENTARIOS INTRODUCTORIOS A LOS PRINCIPIOS ASADIP SOBRE EL ACCESO TRANSNACIONAL A LA JUSTICIA)
}

\author{
TRANSNATIONAL ACCESS TO JUSTICE AND GLOBAL GOVERNANCE \\ (INTRODUCTORY COMMENTS TO THE ASADIP PRINCIPLES ON TRANSNATIONAL \\ ACCESS TO JUSTICE)
}

Javier L. Ochoa Muñoz

Profesor de Derecho Internacional Privado de la Universidad Central de Venezuela y la Universidad Católica Andrés Bello. Email: javierochoa@hotmail.com

Convidado

RESUMEN: Los Principios ASADIP sobre el Acceso Transnacional a la Justicia (TRANSJUS) se presentan como una propuesta de soft law que comprende reglas y enunciados orientados a regular litigios privados transnacionales. Su elemento característico más importante es que están concebidos para contribuir a garantizar los derechos fundamentales, en especial, el derecho de acceso a la justicia, desde una visión de la gobernanza global. Este artículo se limita a exponer algunas consideraciones introductorias sobre ese elemento característico.

El acceso a la justicia se constituye hoy como uno de los derechos humanos de mayor importancia, que no se limita al ámbito de las relaciones jurídicas locales, sino que envuelve también las relaciones jurídicas transnacionales.

A su lado, ha surgido el debate acerca del rol de los tribunales locales y los litigios transnacionales en la articulación de la gobernanza global. Pero el enfoque de la gobernanza está cargado de incertidumbre. Resulta difícil estructurar los valores e intereses comprendidos en esa gobernanza, así como determinar su interrelación con los derechos de los particulares. Sin embargo, se tienen elementos para sostener que el acceso efectivo a la justicia en el ámbito transnacional no solamente favorece los derechos particulares, sino que también contribuye a la realización de los más relevantes valores de la gobernanza global, como el bienestar económico, social y ambiental, así como la protección de los derechos humanos.En este sentido, se hace necesaria una idea de coordinación y cooperación jurídica internacional, que sustituya al paradigma de la plena separación recíproca de las soberanías.

Palabras Clave: Acceso transnacional a la justicia, gobernanza global, litigios internacionales, cooperación jurídica internacional.

ABSTRACT: The ASADIP Principles on Transnational Access to Justice (TRANSJUS) are submitted as a soft law proposal that contains rules aimed at regulating private transnational litigation. The most important characteristic is that they are designed to help guarantee fundamental rights, especially the right of access to justice, from a perspective of global governance. This article just notes some introductory considerations on this characteristic of the principles.Access to justice today is one of the most important human rights, which is not limited to the scope of local legal relations, but also involves transnational legal relations. Next to it, a debate has arisen about the role of local courts and transnational litigation in shaping global governance. Nevertheless, the governance approach is filled of uncertainty. It is difficult to assembly the values and interests included in that governance, as well as to determine their interrelation with the rights of individuals.However, there are elements to support that effective access to justice in the transnational spherenot only helps to favor rights, but also contributes to the fulfilment of the most relevant values of global governance, such as economic and social well-being, environmental protection, 
as well as the protection of human rights.In this sense, an idea of international coordination and legal cooperation becomes necessary, to replace the paradigm of full reciprocal separation of sovereignty.

Key Words: transnational access to justice, global governance, international litigation, international legal assistance.

SUMARIO. 1. Introducción. 2. La evolución y expansión del derecho de acceso a la justicia. 3. El acceso transnacional a la justicia. 3.1. El derecho de acceso transnacional a la justicia como derecho humano. 3.2. Expansión del acceso transnacional a la justicia como derecho humano. 4. El Derecho internacional privado en tiempos de gobernanza global. 5. Gobernanza judicial transnacional. 5.1. ¿Quién gobierna? Determinación judicial de la autoridad de gobernanza. 5.2. ¿Qué le toca a cada quien? Determinación de la distribución de los bienes y la riqueza. 6 . Bienestar global y gobernanza judicial transnacional. 7. El principio de Cooperación jurídica internacional (a modo de conclusión). Referencias.

\section{INTRODUCCIÓN}

Los Principios ASADIP sobre el Acceso Transnacional a la Justicia (TRANSJUS) se presentan como una propuesta de soft law que comprende reglas y enunciados orientados a regular litigios privados transnacionales. Luego de tres años de trabajos, fueron aprobados por la Asociación Americana de Derecho Internacional Privado (ASADIP) en su Asamblea de noviembre de 2016, celebrada en la ciudad de Buenos Aires. ${ }^{1}$

$\mathrm{Su}$ elemento característico más importante es que están concebidos como "estándares mínimos para garantizar el acceso a la justicia, sin discriminación por razón de la nacionalidad o residencia y de conformidad con el Derecho internacional de los derechos humanos y los principios consagrados por la generalidad de las constituciones modernas. A su vez, pretenden constituirse en parte y vector de la gobernanza global, procurando articular los poderes de los Estados en una relación de coordinación y cooperación para el logro de una justicia transnacional efectiva, como presupuesto necesario e impostergable para el bienestar social del mundo globalizado en el que vivimos." "Se trata de contribuir a garantizar los derechos fundamentales, en especial, el derecho de acceso a la justicia, desde una visión de la gobernanza global.

En este mundo, estremecido por su propia interconexión e interdependencia, los litigios transnacionales dejaron de ser una problemática de algunos pocos y de las élites, para constituirse en situaciones ubicuas. ${ }^{3}$ La litigación transnacional ya reclama autonomía como una rama distinta del Derecho, lo cual encuentra justificación en las "necesidades heurísticas de la profesión."4

\footnotetext{
${ }^{1}$ Fueron elaborados por Diego Fernández Arroyo, Alejandro Garro, Eduardo Véscovi y Javier L. Ochoa Muñoz. Disponibles en español, francés, inglés y portugués: http://www.asadip.org/v2/?page_id=231.

${ }^{2}$ Así se expresa en el preámbulo de los principios.

${ }^{3}$ Ochoa Muñoz, Javier y Madrid Martínez, Claudia, Problemas de Acceso Transnacional a la Justicia en el Derecho Internacional Privado, Perspectiva Latinoamericana, en AAVV: Curso de Derecho Internacional, XLI, 2014, Comité Jurídico Interamericano, Organización de Estado Americanos, Washington, D.C., 2015, pp. 330-335.

${ }^{4}$ Véase, Baumgartner, Samuel P., Transnational Litigation in the United States: The Emergence of a New Field of Law, American Journal of Comparative Law, Vol. 55, 2007, esp. p.14. Disponible en: http://ssrn.com/abstract=1008355. Consultado por última vez el 04/04//2018.("In England, for example, transnational litigation practice has evolved from an occasional occurrence of interest mostly to conflicts scholars to an important practical subject during the last 25 years. And in German-speaking Europe, where the subject has been studied as a distinct discipline for considerably longer, the increasingly rapid development of the law at the domestic as well as the European Community level has spawned new textbooks and frequent releases of new editions of those books.") Véase también, Silberman, Linda, Transnational Litigation: Is There a "Field"? A Tribute to Hal Maier, Vanderbilt Journal of Transnational Law, Vol. 39, 2006, pp. 1427-1437. Disponible en: https://www.vanderbilt.edu/wpcontent/uploads/sites/78/Silberman.pdf. Consultado por última vez el 04/04/2018.
}

Revista de Direito Brasileira | São Paulo, SP | v. 20 | n. 8 | p. 336-3363 |Mai./Ago. 2018 
Esa realidad de mundialización omnipresente y avasallante, choca con la concepción jurídica del mundo, dividido en parcelas jurisdiccionales, en soberanías que todavía se conciben recíprocamente separadas, totalmente independientes unas de otras.

Obviamente ese choque no sucede sin dejar lesionados, en algunos casos de gravedad. Las personas de muchos recursos y las grandes empresas, encuentran en la mayoría de las soluciones y herramientas jurídicas actuales, elementos suficientes para hacer valer sus derechos e intereses. Entre la justicia arbitral y los servicios jurídicos altamente calificados, podríamos decir que el Derecho es eficiente en la protección de los intereses entre tales sujetos. Pero los sectores más vulnerables, incluso las personas comunes, así como las PYMES, enfrentan obstáculos a veces infranqueables. ${ }^{5}$

Para éstos la justicia transita herida, en carne viva, caminando sobre brasas y clavos en el contexto transnacional. Los obstáculos al acceso transnacional a la justicia se multiplican exponencialmente en el ámbito transnacional, lo que convierte a estos casos en situaciones de extrema urgencia. Empleando el lenguaje médico, se trata de situaciones de "cuidados intensivos". El Derecho Procesal Civil Internacional se torna en una suerte de "Derecho de emergencias", o al menos así debe concebirse si se quiere que realmente cumpla su función de procurar la justicia. El mínimo error de una regulación o de su aplicación, la menor dilación, incluso la falta de un juez activista que sepa interpretar y aplicar las normas de manera eficiente, se traduce en una violación al derecho de acceso a la justicia.

Un sistema jurídico que no tome especiales precauciones para resolver las situaciones y necesidades procesales específicas de las personas en sus relaciones transnacionales, es un sistema obsoleto e injusto.

Limitamos el alcance de este artículo a algunas consideraciones sobre ese elemento característico de los principios, a objeto de que sirvan como comentarios introductorios de los mismos. Dejamos para una próxima oportunidad la explicación y su desarrollo detallado.

\section{LA EVOLUCIÓN Y EXPANSIÓN DEL DERECHO DE ACCESO A LA JUSTICIA}

El acceso a la justicia se ha convertido en el sellodistintivo de la civilización moderna, ${ }^{6}$ una especie de super derecho,la garantía de las garantías, ${ }^{7}$ la puerta de entrada al reclamo de los otros derechos humanos, ${ }^{8}$ un verdadero "derecho al Derecho." Ya es un lugar común citar a Cappelletti y Garth al afirmar: "El acceso efectivo a la justicia se puede considerar, entonces, como el requisito más básico -'el derecho humano' más fundamental- en un sistema

\footnotetext{
${ }^{5}$ Es de destacar que, según estudios de la CEPAL, las microempresas y las pymes, constituyen un componente fundamental del entramado productivo en la región, constituyendo alrededor de $99 \%$ del total de empresas, al tiempo que proveen cerca de $67 \%$ de las plazas de trabajo en América Latina y el Caribe Véase información publicada en el portal oficial de la CEPAL, específicamente en: https://www.cepal.org/es/temas/pymes/acerca-microempresaspymes. Las mismas cifras se observan en la Unión Europea, donde además las PYMES aportan el 85\% de los nuevos puestos de trabajo Véase información publicada en el portal oficial de la Unión Europea, específicamente en: https://europa.eu/european-union/topics/enterprise es. Consultado por última vez el 04/04/2018.

${ }^{6}$ Declaración del Secretario de Justicia del Reino Unido, Kenneth Clark, en noviembre de 2016. Disponible en: https://www.theguardian.com/law/2011/oct/06/access-to-justice-legal-aid-cuts. Consultado por última vez el 04/04/2018.

7 Mabarotto Lugaro, Jorge A., Un derecho humano esencial: el acceso a la justicia, Anuario de Derecho Constitucional Latinoamericano, Instituto de Investigaciones Jurídicas de la UNAM, 2003, pp. 291 ss., esp. p. 295. En: http://www.juridicas.unam.mx/publica/librev/rev/dconstla/cont/2003/pr/pr16.pdf. Consultado por última vez el 04/04/2018.

${ }^{8}$ Ortiz Ahlf, Loreta, El derecho de acceso a la justicia, en AAVV, Obra en homenaje a Rodolfo Cruz Miramontes. Tomo II. UNAM. México D.F., 2008, pp. 403-422, esp. p. 408. Disponible en: https://archivos.juridicas.unam.mx/www/bjv/libros/6/2547/20.pdf. Consultado por última vez el 04/04/2018.

${ }^{9}$ Cançado Trindade, Antônio Augusto, Tratado de Direito Internacional dos Direitos Humanos, tomo III, Porto Alegre/Brasil, S.A. Fabris Ed., 2002, p. 524.
}

Revista de Direito Brasileira | São Paulo, SP | v. 20 | n. 8 | p. 336-363 |Mai./Ago. 2018 
legal igualitario moderno, que pretenda garantizar y no solamente proclamar los derechos de todos". 10

Aun cuando sus contornos precisos no están bien definidos todavía, el derecho de acceso a la justicia tiende a fortalecerse y expandirse. Por supuesto, este no escapa de la corriente evolutiva y de la universalización de los derechos fundamentales. En su concepción original se hallaba limitado a la dimensión formal, como posibilidad de acceder a la jurisdicción. ${ }^{11}$ Pero el desarrollo progresivo de los derechos humanos determinó que ese acceso debía ser real y no tan solo teórico, lo cual exige permanentes esfuerzos y desarrollos. ${ }^{12}$

A partir de la Declaración Americana de los Derechos y Deberes del Hombre ${ }^{13}$ y la Declaración Universal de los Derechos Humanos, ${ }^{14}$ ambas de 1948, el derecho de acceso a la justicia evoluciona y se expande a través de los más importantes tratados internacionales sobre derechos humanos. ${ }^{15}$

Es reconocido por el Pacto Internacional de Derechos Civiles y Políticos, de 16 de diciembre de $1966{ }^{16}$ el Convenio Europeo para la Protección de los Derechos Humanos y las Libertades Fundamentales, de 4 de noviembre de 1950 (CEDH) ${ }^{17}$ la Convención Americana de Derechos Humanos (Pacto de San José), de 22 de noviembre de 1969, ${ }^{18}$ la Carta Africana sobre Derechos Humanos y de los Pueblos, de 27 de julio de 1981, ${ }^{19}$ y el Tratado de Funcionamiento de la Unión Europea, ${ }^{20}$ entre otros. ${ }^{21}$

Es cierto, como sugiere también S.I. Strong, que casi todos estos instrumentos contienen regulaciones muy generales, e incluso vagas o insuficientes, sobre la definición del derecho de acceso a la justicia. La forma de consagrarlo dista mucho de ser homogénea, y la diversidad en la que se concibe, arroja dudas acerca de si se trata de la misma figura. Algunas regulaciones parecen apuntar más hacia el ámbito penal, mientras otras se detienen en la jurisdicción civil. ${ }^{22}$

${ }^{10}$ Cappelletti, Mauro y Garth, Bryant, El acceso a la justicia. La tendencia en el movimiento mundial para hacer efectivos los derechos; trad. de Mónica Miranda, FCE, México, 1996, pp. 13.

${ }^{11}$ Ibid. p. 11.

${ }^{12}$ Mabarotto Lugaro, Jorge A., Un derecho humano esencial..., ob. cit., p. 293. Véase también, OC-18/03 Corte IDH 17/09/2003, Solicitada por los Estados Unidos Mexicanos (Condición jurídica y derechos de los migrantes indocumentados), $\quad$ parr. $126 . \quad$ Disponible en: http://www.acnur.org/t3/fileadmin/Documentos/BDL/2003/2351.pdf?view=1. Consultado por última vez el 04/04/2018.

${ }^{13}$ Art. XVIII.

${ }^{14}$ Arts.8, 9 y 10 .

${ }^{15}$ En los trabajos preparatorios de la Declaración Universal de Derechos Humanos, el proyecto propiamente dicho fue elaborado en la Comisión de Derechos Humanos de Naciones Unidas, por un Grupo de Trabajo, entre mayo de 1947 y junio de 1948. A partir de septiembre de 1948, el proyecto de Declaración pasó al examen de la III Comisión de la Asamblea General de Naciones Unidas. El artículo 8, que se refiere al derecho a un recurso efectivo, fue insertado en la etapa final de los trabajos preparatorios, cuando ya se encontraba bajo el examen de la III Comisión, dentro de la cual no encontró objeción alguna, y fue luego aprobado por unanimidad en el plenario de la Asamblea General. La iniciativa del artículo provino de delegaciones de los Estados latinoamericanos. "Se puede incluso considerar que el artículo 8 (sobre el derecho a un recurso efectivo) representa la contribución latinoamericana par excellence a la Declaración Universal.” Voto Razonado del Juez Antônio Augusto Cançado Trindade a la decisión de la Corte IDH, del caso López Álvarez c. Honduras de 01/02/2006, párrs. 5 y 6.

${ }^{16}$ Art. 14.

${ }^{17}$ Art. 6.

${ }^{18}$ Arts. 8 y 25

19 Art. 7.

${ }^{20}$ Art. 67(4) antiguo, 29 TUE; y art.81(2).

${ }^{21}$ Su reconocimiento también resalta en la Carta de los Derechos Fundamentales de la Unión Europea, de 18 de diciembre de 2000, art. 47.

22 Strong, S.I., General Principles of Procedural Law and Procedural Jus Cogens, 122 Penn State Law Review (2018 Forthcoming); 1 de Agosto 2017, University of Missouri School of Law Legal Studies Research Paper No. 2017-20. Pp. 14-15. Disponible en: https://ssrn.com/abstract=3011947. pp. 14 y 15. Consultado por última vez el 04/04/2018.

Revista de Direito Brasileira | São Paulo, SP | v. 20 | n. 8 | p. 336-3363 |Mai./Ago. 2018 
Sin embargo, la jurisprudencia local e internacional, así como la doctrina, tienden a unificar el concepto del derecho de acceso a la justicia (aunque no exista un concepto uniforme), tomando indiferenciadamente como base las regulaciones heterogéneas de los tratados internacionales. $^{23}$

La importancia del derecho de acceso a la justicia y la constatación de los problemas que enfrentan las personas en esta materia, han generado gran preocupación a nivel global. Incluso se ha determinado que la realización de este derecho tiene importantes consecuencias en la consolidación de la democracia y la superación de la pobreza, así como la consecución de la seguridad ciudadana, ${ }^{24}$ la paz social y el desarrollo de los pueblos. ${ }^{25}$

En el ámbito de la jurisprudencia internacional la expansión y el fortalecimiento del derecho de acceso a la justicia se ha hecho sentir vigorosamente.

Aunque el artículo 6 del CEDH se refiere a un "juicio justo", el Tribunal Europeo de Derecho Humanos (TEDH) ha aclarado desde temprano que el derecho de acceso a la justicia está allí implícitamente consagrado y su respeto debe ser efectivo y no meramente teórico. ${ }^{26}$ Igualmente, aunque la asistencia jurídica gratuita solo está prevista explícitamente en ese precepto respecto de los procesos de carácter penal (art.6.3(c)), el TEDH ha venido reconociendo desde tiempo atrás que el otorgamiento de asistencia jurídica gratuita en el ámbito de los procesos civiles es una de las obligaciones positivas exigidas a los Estados para asegurar la efectividad del acceso a la justicia. ${ }^{27}$

Estadísticamente, el artículo $6 \mathrm{CEDH}$ es el precepto más analizado e interpretado por TEDH. ${ }^{28}$ Según se desprende de su base de datos, este Tribunal ha citado dicha norma más de 28.000 veces. $^{29}$

Por su parte, los pronunciamientos de la Corte Interamericana de Derechos Humanos (Corte IDH) también han sido nutridos en relación a la importancia del derecho de acceso a la justicia. Para este órgano jurisdiccional la garantía a un recurso efectivo "constituye uno de los pilares básicos, no solo de la Convención Americana, sino del propio Estado de Derecho en una sociedad democrática en el sentido de la Convención." ${ }^{30}$ Entre los aportes de la Corte IDH vale destacar dos que consideramos esenciales: i.- la promoción de una concepción amplia (lato

\footnotetext{
${ }^{23}$ Véase Francesco Francioni, The Rights of Access to Justice under Customary International Law, en AAVV, Acces to Justice as a Human Right, Academy of Eropean Law, Eruropean University Institute y Oxford University Press, Nueva York, 2007, pp. 1-55, esp. p. 25.

${ }^{24} \mathrm{La}$ Asamblea General de OEA ha manifestado reiteradamente "(q)ue ampliar el acceso a la justicia es fundamental para el pleno ejercicio de los derechos humanos y la gobernabilidad democrática; asimismo, es indispensable en el marco de estrategias exitosas de seguridad ciudadana, así como para la eliminación de la pobreza y la desigualdad..." AG/RES. 2703 (XLII-O/12) Fortalecimiento de las actividades del programa interamericano de facilitadores judiciales, aprobada en la segunda sesión plenaria, celebrada el 4 de junio de 2012. En: http://www.oas.org/es/sla/ddi/docs/AG-RES 2703 XLII-O-12.pdf. En la misma directriz, véanse las siguientes resoluciones: OEA/Ser.P, AG/RES. 2801 (XLIII-O/13) 5 junio 2013. En: http://www.oas.org/es/sla/ddi/docs/AGRES 2801 XLIII-O-13.pdf. Las mismas expresiones habían sido ya proferidas por dicho órgano en las resoluciones AG/RES. 2714 (XLII-O/12) de 4 de junio de 2012 (http://www.oas.org/es/sla/ddi/docs/AG-RES 2714_XLII-O12.pdf) y AG/RES. 2656 (XLI-O/11) de 7 de junio de 2011 (http://www.oas.org/es/sla/ddi/docs/AGRES 2656 XLI-O-11.pdf).

${ }_{25}$ PNUD, Manual de políticas públicas para el acceso a la justicia, Materiales de Trabajo, 2005, p. 13, en: http://www.justiciaviva.org.pe/acceso_justicia/documentos/Manual.pdf. Consultado por última vez el 04/04/2018.

${ }^{26}$ Caso Golder c. Reino Unido, sentencia del TEDH de 21 de febrero de 1975, §.32 y 36.

${ }^{27}$ Caso Airey c. Irlanda, sentencia del TEDH de 9 de octubre de 1979, §.26.

${ }^{28}$ Ciro Milione, El derecho a la tutela judicial efectiva entre el Tribunal de Justicia de la Unión Europea y el Tribunal Europeo de Derechos Humanos. Disponible en: http://congresoace.deusto.es/wp-content/uploads/2016/01/Mesa-1Ciro-Milione-BIS.pdf. Consultada por última vez el 02/10/2017.

${ }^{29}$ Strong, SI, General Principles of Procedural Law and Procedural Jus Cogens, ob. cit. El dato fue extraído por la autora colocando los términos "article 6" en el motor de búsqueda de la base de datos en: http://echr.coe.int/Pages/home.aspx? $\mathrm{p}=$ caselaw/HUDOC\&c=.

${ }^{30}$ Corte IDH., Castillo Páez c. Perú del 03/11/1997, párr. 82. Desde entonces esta ha sido la posición reiterada de la Corte.
} 
sensu) del derecho de acceso a la justicia que envuelve a la generalidad de las garantías procesales, entre ellas, el debido proceso y el derecho a un recurso efectivo; ${ }^{31} \mathrm{y}$ ii. - su consideración como una parte del contenido material del ius cogens. ${ }^{32}$ Esta última idea ya ha encontrado eco en la jurisprudencia argentina. ${ }^{33}$

En el contexto constitucional comparado, se observa también una extraordinaria expansión del derecho de acceso a la justicia. Exhaustivos estudios han dado cuenta de un significativo incremento del porcentaje de constituciones que consagran este derecho a partir de la Segunda Guerra Mundial, especialmente entre 1946 y 2006. Aunque ese porcentaje decreció de un 68\% entre 1946 y 1956, hacia un 62\% en 1976, de allí en adelante escaló aceleradamente hasta un $86 \%$ en $2006 .{ }^{34}$ Ya en 2006 el acceso a la justicia se encontraba entre las once disposiciones más comunes en las constituciones del mundo, y su aparición en tantos textos constitucionales llevaría a afirmar que se trata de una parte de la práctica global y general del constitucionalismo. ${ }^{35}$ Un dato curioso, que pone de relieve la preminencia del derecho de acceso a la justicia en el contexto del constitucionalismo moderno, surge de la comparación entre este derecho y la prohibición de la tortura. El porcentaje de constituciones que contemplaban la prohibición de la tortura era de $37 \%$ en $1946,37 \%$ en $1956,41 \%$ en $1966,45 \%$ en $1976,56 \%$ en

\footnotetext{
${ }^{31}$ Cançado Trindade ha sido uno los más vehementes promotores del derecho de acceso a la justicia, no solo en su momento, como juez de la Corte IDH, sino también en sus diferentes aportes doctrinales. Entre sus numerosos votos razonados sobre sentencias de la Corte IDH, se detuvo a explicar la concepción ampliada del derecho de acceso a la justicia. Lato sensu, el derecho de acceso a la justicia "no se reduce al acceso formal, stricto sensu, a la instancia judicial (tanto interna como internacional), sino comprende, además, el derecho a la prestación jurisdiccional, y encuéntrase subyacente a disposiciones interrelacionadas de la Convención Americana (como los artículos 25 y 8), además de permear el derecho interno de los Estados Partes. El derecho de acceso a la justicia, dotado de contenido jurídico propio, significa, lato sensu, el derecho a obtener justicia. Configúrase, así, en suma, como el derecho a la propia realización de la justicia." Véase, Voto Razonado del Juez A.A. Cançado Trindade a la decisión de la Corte IDH, del caso López Álvarez c. Honduras de 01/02/2006, párr. 51. En su argumentación, Cançado Trindade defiende la corriente jurisprudencial de la Corte y apunta: "Considero esta evolución jurisprudencial un patrimonio jurídico del sistema interamericano de protección y de los pueblos de nuestra región, y me opongo firmemente a cualquier intento de desconstruirlo. La Corte ha sido fiel a su posición de vanguardia hasta la fecha. En su ya célebre Opinión Consultiva n. 16, sobre El Derecho a la Información sobre la Asistencia Consular en el Marco de las Garantías del Debido Proceso Legal (del 01.10.1999), que ha servido de inspiración a la jurisprudencia internacional in statu nascendi sobre la materia (como es ampliamente reconocido en la bibliografía especializada), la Corte una vez más tomó en conjunto el derecho a un recurso efectivo y las garantías del debido proceso legal (artículos 25 y 8 de la Convención)." (párr. 21)

${ }^{32}$ La Corte IDH reconoció en el caso Goiburú que: "El acceso a la justicia constituye una norma imperativa de Derecho Internacional y, como tal, genera obligaciones erga omnes para los estados de adoptar medidas que sean necesarias para no dejar en la impunidad esas violaciones, ya sea ejerciendo su jurisdicción para aplicar su derecho interno y el derecho internacional para juzgar y, en su caso, sancionar a los responsables, o colaborando con otros estados que lo hagan o procuren hacerlo." Corte IDH Caso Goiburú y otros Vs. Paraguay de 22/09/2006 (Fondo, Reparaciones y Costas), párr. 131. El mismo criterio se reiteró en la sentencia del caso Caso La Cantuta c..Perú de 29/11/2006 (Fondo, Reparaciones y Costas), párr. 160. Véase también, Florabel Quispe Remón, Ius cogens en el Sistema Interamericano: Su relación con el debido proceso, Universidad del Norte, No. 34, Barranquilla, 2010, pp. 42-78, esp. p. 47.

${ }^{33}$ SD 70573 de la Sala V de la Cámara Nacional de Apelaciones del Trabajo, Autos: González, Protacio C/ Berkley Internacional Art S.A. de fecha 31 de marzo de 2008."No puede haber duda de que las garantías fundamentales, comunes al Derecho Internacional de los Derechos Humanos y al Derecho Internacional Humanitario, tienen una vocación universal al aplicarse a todas y cualesquiera circunstancias, conforman un derecho imperativo (perteneciendo al ius cogens), y acarrean obligaciones erga omnes de protección. Desde esta perspectiva, las normas reguladoras del procedimiento ante las comisiones médicas vulneran el derecho de acceso a la justicia que forma parte del ius cogens."

${ }^{34}$ Law, David S. y Versteeg, Mila, The Declining Influence of the United States Constitution, 87 N.Y.U. L. REV. 762, 773-75 tbl.1 (2012). Cit. en Whytock, Christopher A., Foreign State immunity and the right to court access, University of California, Irvine School of Law, Legal Studies Research Paper Series No. 2014-10, p. 2053. Disponible en: https://papers.ssrn.com/sol3/papers.cfm?abstract id=2383372. Consultado por última vez el 04/04/2018.

${ }^{35}$ Whytock, Christopher A., Foreign State immunity and the right to court access, ob. cit., p. 2053.
}

Revista de Direito Brasileira | São Paulo, SP | v. 20 | n. 8 | p. 336-3363 |Mai./Ago. 2018 
1986, 80\% en 1996, y 84\% en 2006, en todos esos años su porcentaje es menor al de consagración del derecho de acceso a la justicia. ${ }^{36}$

Esta consagración extendida en el Derecho positivo internacional y en el Derecho constitucional, constituye una base sólida para la demostración de que acceso a la justicia también emerge como una regla consuetudinaria y como un principio general del Derecho internacional.

\section{EL ACCESO TRANSNACIONAL A LA JUSTICIA}

La mayor parte de las preocupaciones y esfuerzos relacionados con el acceso a la justicia, suelen apuntar a las dificultades internas que se presentan en el ámbito local de cada Estado. Pero es evidente que los obstáculos al acceso a la justicia se acentúan de manera exponencial en el contexto del proceso civil transnacional.

Por un lado, la asistencia jurídica profesional es mucho más costosa y difícil de obtener cuando el asunto trasciende las fronteras de un Estado, pues se trata de asuntos manejados por muy pocos especialistas, de modo que la asistencia profesional de calidad tiende a ser costosa y difícil de obtener. Incluso entre los despachos de abogados de alto nivel, muchos suelen estar desprovistos de profesionales con conocimientos suficientemente sólidos en litigación internacional. Así, no solamente la población de bajos recursos queda limitada en el acceso a la justicia en estos asuntos, sino también las personas comunes, así como las micro, pequeñas y medianas empresas. ${ }^{37}$ Los procesos con elementos internacionales tienden demorarse mucho más y el desconocimiento de los jueces en materia de litigios transnacionales suele ser mucho más acentuado que en cualquier ámbito interno. ${ }^{38}$

Las asimetrías entre las partes suelen incrementarse más en la esfera de las relaciones privadas internacionales. Las corporaciones y personas con más recursos, pueden acceder a servicios jurídicos altamente especializados, con agencias en múltiples jurisdicciones, lo que les permite planificar y ejecutar estrategias de litigio transnacionales, incoando múltiples procesos al mismo tiempo, evacuando pruebas en distintas jurisdicciones, ejecutando u oponiéndose medidas cautelares, etc. ${ }^{39}$ También el reclamo de los intereses difusos y colectivos plantea especiales complejidades en el ámbito internacional, ${ }^{40}$ pues las víctimas suelen ser personas de escasos

\footnotetext{
${ }^{36}$ Ibid. p. 2055.

${ }^{37}$ Véase, Baumgartner, Samuel P., Transnational Litigation in the United States..., ob. cit., p. 7-8. "Moreover, transnational litigation is often complex, expensive, and therefore lucrative for the legal service market. Not surprisingly, then, top firms increasingly make sure they have attorneys who are familiar with that turf. The result is that a growing but still select number of lawyers are conversant with the foreign alternatives to litigation in the United States as well as with the most attractive exit option - international arbitration - while most other attorneys, many litigants, and law reformers are not. Thus, we have identified the first feature that distinguishes transnational litigation from purely domestic litigation: Its effect is not only that some litigants receive superior advice and thus achieve better outcomes, but also that there is a group of litigants that is able to go elsewhere to influence legislative and, perhaps, executive action as well as to litigate and thus potentially to subvert the policies of domestic litigation procedure in ways not expected by lawmakers and judges."

${ }^{38}$ Ibid.

${ }^{39}$ Ibid.

${ }^{40}$ Sin embargo, también se reconoce que la perspectiva internacional permite a las víctimas, en algunos casos, elegir jurisdicciones más favorables para obtener mayores indemnizaciones. No obstante, algunos obstáculos muy relevantes han emergido en este ámbito, al menos en el contexto de la jurisdicción norteamericana que generan nuevas brechas de acceso a la justicia. Ver: Whytock, Christopher A. y Burke Robertson, Cassandra, Forum non conveniens and the enforcement of foreign judgments, Columbia Law Review, 2011, Vol. 111:144, pp. 1444 ss. El más reciente revés surgido para esta posibilidad fue la sentencia de la Corte Suprema de los Estados Unidos en el caso Kiobel vs. Shell 133 S.Ct. 1659 (2013).
}

Revista de Direito Brasileira | São Paulo, SP | v. 20 | n. 8 | p. 336-363 |Mai./Ago. 2018 
recursos, prácticamente imposibilitadas de viajar, comprender idiomas diferentes, elegir y pagar servicios jurídicos, etc. $^{41}$

Obviamente, si entendemos el acceso transnacional a la justicia como una parte inescindible del derecho de acceso a la justicia en general, en una realidad de mundialización como la que enfrentamos, estas circunstancias deben llamar a la reflexión y la búsqueda de soluciones más efectivas.

\subsection{El derecho de acceso transnacional a la justicia como derecho humano}

Ante las circunstancias expuestas en el punto anterior, cabe la interrogante acerca de si existe un derecho al acceso trasnacional a la justicia. ${ }^{42}$

Para nosotros, el punto de partida actual del acceso trasnacional es el mismo derecho humano de acceso a la justicia, tal como fue inicialmente concebido en el Derecho Internacional y local. No vemos argumentos válidos, ni desde el Derecho local ni desde el internacional, para sostener que el acceso a la justicia deba estar limitado sólo a los casos o situaciones jurídicas aisladas en una sola jurisdicción. Es decir, la concepción del derecho de acceso a la justicia en el orden civil o mercantil, no puede estar limitada a las situaciones jurídicas cuyos elementos se encuentren confinados en la jurisdicción del foro. Semejante afirmación, además de ser absolutamente irrazonable, anularía en gran medida la eficacia del derecho de acceso a la justicia en la realidad de mundialización a la que asistimos. La unidad en la que se comprenden las diversas manifestaciones del derecho de acceso a la justicia, es la base esencial para responder a la pregunta acerca de la verdadera existencia de un derecho de acceso internacional o transnacional a la justicia, es decir, un derecho a la tutela judicial de los derechos e intereses de las personas respecto de sus relaciones jurídicas de carácter privado en el ámbito global. Los principios de universalidad, indivisibilidad y progresividad de los derechos humanos determinan de manera ineludible la extensión de ese acceso al contexto transnacional.

Ya no resulta necesaria la búsqueda de una regla precisa del Derecho internacional que imponga el deber a los Estados de prestar servicios jurisdiccionales eficientes a los casos pluriconetados. ${ }^{43}$ La obligación se deriva clara y directamente del núcleo general del derecho de acceso a la justicia, cuya fragmentación según la localización de las situaciones, resulta inadmisible desde todo punto de vista. La prestación de la tutela judicial es una obligación erga omnes de los Estados, lo que impone el deber de brindar esa tutela a todas las personas.

Ello no significa que este derecho sea ilimitado, o que no pueda encontrar restricciones en función de una diversidad de circunstancias. ${ }^{44}$

\footnotetext{
${ }^{41}$ Véase, Ochoa Muñoz, Javier y Madrid Martínez, Claudia, Problemas de Acceso Transnacional a la Justicia..., ob. cit., , pp. 330-335.

${ }^{42}$ Whitock, Christopher A, Foreign State Immunity and the Right to Court Access, ob. Cit., p. 2048. "Although some scholars argue that there is an international legal right to court access, this Part's central argument is more modest: the right to court access, whether or not it has become a legally binding rule of international law, is widely accepted and increasingly legalized."

${ }^{43}$ Cfr. Francioni, Francesco, The Rights of Access to Justice under Customary International Law, en AAVV, Acces to Justice as a Human Right, Academy of Eropean Law, Eruropean University Institute y Oxford University Press, Nueva York, 2007, pp. 1-55, esp. p. 9.

${ }^{44}$ Respecto de las limitaciones al derecho de acceso a la justicia, véase: Sciso, Elena,Italian Judges' Point of View on Foreign States' Immunity, Vanderbilt Journal of Transnational Law, Vol. 44, 2011, pp. 1201-1231, esp. p. 1213. Disponible en: https://www.vanderbilt.edu/wp-content/uploads/sites/78/Scisco-pdf. Consultado por última vez el 04/03/2018. También, Francioni, Francesco, The Rights of Access to Justice under Customary International Law, ob. cit., p. 38-39.
} 


\subsection{Expansión del acceso transnacional a la justicia como derecho humano}

El reconocimiento directo del derecho de acceso transnacional a la justicia o de una tutela jurídica efectiva en el ámbito transnacional, parece haberse difundido a partir del Convenio de La Haya sobre el Acceso Internacional a la Justicia de 1980. Los Estados signatarios, "deseando facilitar el acceso internacional a la justicia", ${ }^{45}$ concluyeron este instrumento, cuyo objetivo fundamental es facilitar, para los nacionales o residentes de un Estado parte del Convenio, el acceso a la justicia en los otros Estados parte del Convenio. ${ }^{46}$

Probablemente bajo los influjos de este Convenio, la mayor parte de la doctrina que se ocupó del acceso trasnacional a la justicia y las reformas legislativas correspondientes, se centraron especialmente en la igualdad entre los litigantes foráneos y locales, eliminándose las cauciones y extendiendo a aquellos la asistencia jurídica subvencionada que se confería a estos. ${ }^{47}$

Posteriormente se generó un movimiento doctrinal, acompañado de regulaciones legislativas y pronunciamientos jurisprudenciales que incorporaron la idea del foro de necesidad (forum necessitatis). ${ }^{48}$

En este marco evolutivo tuvo lugar un incremento muy significativo convenios internacionales y de ratificaciones de los mismos, relativos a los aspectos del Derecho Procesal Civil Internacional. ${ }^{49}$ Estos asuntos habían quedado prácticamente marginados de las discusiones doctrinales. Parecen haber sido las necesidades del creciente tráfico internacional las que impulsaron los cambios en la doctrina y la incorporación de las convenciones. ${ }^{50}$ Pero es de advertir, que buena parte de estos cambios no estaban sustentados directamente en la idea del acceso a la justicia. La necesidad de dar mejor soporte jurídico al comercio internacional ha sido también la razón detrás de los mismos. ${ }^{51}$

\footnotetext{
${ }^{45}$ Préambulo del Convenio.

${ }^{46}$ Outline Hague Access to Justice Convention, Hague Convention of 25 October 1980 on International Access to Justice. En: http://www.hcch.net/index es.php?act=publications.details\&pid=2784\&dtid=28. Consultado por última vez el 06/04/2018.

${ }^{47}$ Véase, en particular, el interesante artículo de Rábago Dorbecker, Miguel, El acceso a la justicia en casos de litigio internacional: foro de necesidad, asistencia judicial gratuita y cautio iudicato solvi. En AAVV, Anuario del Departamento de Derecho de la Universidad Iberoamericana, 2004, No 34, pp. 81 ss.

48 Véase Fresnedo de Aguirre, Cecilia, Public Policy: Common Principles in the American States, Recueil des Courses,Vol. 379, 2016, pp.., 329 y sig. Entre los ejemplos de legislaciones que consagraron expresamente el forum necessitatis, se encuentran la Ley Federal Suiza de Derecho Internacional Privado de 1987 (art. 3), el Código Civil de la Provincia de Quebec de 1991 (art. 3136), el Código Federal de Procedimiento Civil de México de (Art. 565), el Código Civil Belga de 2004 (art. 11). Más recientemente, también ha sido incorporada en la Ley de Derecho Internacional Privado Dominicana de 2014 (art. 21), en el Código Civil y Comercial de la Nación argentino de 2015 (Art. 2602) y en el proyecto de Ley de Derecho Internacional Privado Uruguaya de 2016 (Art. 57.8.e y 57.9). En Argentina, la figura ya había sido incorporada por la jurisprudencia de la Corte Suprema de Justicia en el caso E. Cavura c.A Vlasov en 1960. En una concepción restringida únicamente a medidas provisionales de protección de las personas que encuentren dentro del territorio, el foro de necesidad también ha sido previsto en la Ley de Derecho Internacional Privado venezolana (art. 47). Esta misma concepción limitada fue acogida por los Principios ALI/UNIDORIT sobre el Proceso Civil Transnacional (Principio 2.3).

${ }^{49}$ Véase, Ochoa Muñoz, Javier L., La Cooperación Jurídica en el Siglo Actual, Desarrollo Histórico y Desafíos Actuales, en AAVV: Cuestiones Complejas en los Procesos de Restitución Internacional de Niños en Latinoamérica, Porrúa, Buenos Aires, 2017.

${ }^{50}$ Fernández Arroyo, Diego P., Aspectos esenciales de la competencia judicial internacional en vistas de su reglamentación interamericana, en AAVV, Estudios de Derecho Internacional, Libro Homenaje al Profesor Santiago Benadava, T. II (Derecho internacional privado), Santiago, Librotecnia, 2008, pp. 119. Fernández Arroyo, Diego, El Derecho internacional en el diván, Tribulaciones de un ser complejo, en AAVV, Derecho internacional privado y derecho de la integración, Libro Homenaje a Roberto Ruiz Díaz Labrano, Asunción, CEDEP, 2013, pp. 17-35, esp. p. 27.

51 Véase Goicoechea, Ignacio, Nuevos Desarrollos en la Cooperación Jurídica Internacional en Materia Civil y Comercial, Revista de la Secretaria Permanente de Revisión, Año 4, No 7, Mayo 2016, pp. 127 -151, esp. p. $129-130$. Disponible en: http://www.revistastpr.com/index.php/rstpr/article/view/19. El autor comenta y cita buenos ejemplos
}

Revista de Direito Brasileira | São Paulo, SP | v. 20 | n. 8 | p. 336-363 |Mai./Ago. 2018 
La idea del acceso transnacional a la justicia se contempla también en el tratado de Funcionamiento de la Unión Europea:

Artículo 67 (antiguo artículo 61 TCE y antiguo artículo 29 TUE)

1. La Unión constituye un espacio de libertad, seguridad y justicia dentro del respeto de los derechos fundamentales y de los distintos sistemas y tradiciones jurídicos de los Estados miembros.

...

4. La Unión facilitará la tutela judicial, garantizando en especial el principio de reconocimiento mutuo de las resoluciones judiciales y extrajudiciales en materia civil. $^{52}$

Una dirección similar se observa en el Código Modelo de Cooperación Interjurisdiccional para Iberoamérica, preparado por el Instituto Iberoamericano de Derecho Procesal, en cuya exposición de motivos se expresa:

La tutela judicial transnacional es una exigencia de los tiempos actuales, ya que constantemente las relaciones jurídicas, sobre diversos aspectos, traspasan las fronteras de un Estado. Asegurar la efectividad de una tutela judicial sin fronteras significa mucho más que solamente reconocer las decisiones judiciales extranjeras ejecutoriadas pronunciadas en procesos de conocimiento.

Todo lo que sea necesario para asegurar la efectividad de la jurisdicción debe estar comprendido en la idea de una tutela judicial transnacional, como ser: las medidas de urgencia, los actos de ejecución, los actos destinados a la comunicación procesal o incluso los actos probatorios. Poco importa si se trata de Derecho Público o Derecho Privado; de la misma manera, la jurisdicción ha

de la manera en que la seguridad jurídica y el acceso a la justicia generan un impacto concreto en el desarrollo de los negocios internacionales.

${ }^{52}$ Asimismo, se establece en el art. 81 (antiguo artículo 65 TCE):

1. La Unión desarrollará una cooperación judicial en asuntos civiles con repercusión transfronteriza, basada en el principio de reconocimiento mutuo de las resoluciones judiciales y extrajudiciales. Esta cooperación podrá incluir la adopción de medidas de aproximación de las disposiciones legales y reglamentarias de los Estados miembros.

2. A los efectos del apartado 1, y en particular cuando resulte necesario para el buen funcionamiento del mercado interior, el Parlamento Europeo y el Consejo adoptarán, con arreglo al procedimiento legislativo ordinario, medidas para garantizar:

a) el reconocimiento mutuo, entre los Estados miembros, de las resoluciones judiciales y extrajudiciales, así como su ejecución;

b) la notificación y el traslado transfronterizos de documentos judiciales y extrajudiciales;

c) la compatibilidad de las normas aplicables en los Estados miembros en materia de conflictos de leyes y de jurisdicción;

d) la cooperación en la obtención de pruebas;

e) una tutela judicial efectiva;

f) la eliminación de los obstáculos al buen funcionamiento de los procedimientos civiles, fomentando si es necesario la compatibilidad de las normas de procedimiento civil aplicables en los Estados miembros;

g) el desarrollo de métodos alternativos de resolución de litigios;

h) el apoyo a la formación de magistrados y del personal al servicio de la administración de justicia.

3. No obstante lo dispuesto en el apartado 2, las medidas relativas al Derecho de familia con repercusión transfronteriza se establecerán por el Consejo, con arreglo a un procedimiento legislativo especial. El Consejo se pronunciará por unanimidad, previa consulta al Parlamento Europeo.

El Consejo, a propuesta de la Comisión, podrá adoptar una decisión que determine los aspectos del Derecho de familia con repercusión transfronteriza que puedan ser objeto de actos adoptados mediante el procedimiento legislativo ordinario. El Consejo se pronunciará por unanimidad, previa consulta al Parlamento Europeo.

La propuesta a que se refiere el párrafo segundo se comunicará a los Parlamentos nacionales. En caso de que un Parlamento nacional notifique su oposición en los seis meses posteriores a la comunicación, la decisión no será adoptada. En ausencia de oposición, el Consejo podrá adoptar la decisión.

Revista de Direito Brasileira | São Paulo, SP | v. 20 | n. 8 | p. 336-3363 |Mai./Ago. 2018 
de ser efectiva y estar pautada en los mismos principios e ideas de la justicia transnacional." ${ }^{, 53}$

En su Judgments Project, la Conferencia de La Haya ha venido señalando la importancia de derribar las barreras y obstáculos que presenta la litigación internacional, advirtiendo que la necesidad global de soluciones efectivas en esta materia solo se acrecentará. ${ }^{54}$ Las mismas necesidades fueron en su momento observadas por el American Law Institute y por UNIDROIT al elaborar sus Principios y Reglas del Derecho Procesal Civil Transnacional. ${ }^{55}$

En el contexto del Derecho comparado el reconocimiento del derecho de acceso trasnacional a la justicia, ya encuentra al menos una manifestación relevante. En España la reciente Ley de Cooperación Jurídica Internacional en Materia Civil, ${ }^{56}$ establece: Art. 3 (3) "En la interpretación y aplicación de la presente ley se procurará asegurar una tutela judicial internacionalmente efectiva de los derechos e intereses legítimos de los particulares."57

Podríamos decir que con el impulso de la "tercera ola" de reformas hacia el mejoramiento del acceso justicia, que describieron Cappelletti y Garth, ${ }^{58}$ se ha activado el

${ }^{53}$ Elaborado por la Comisión de Revisión de la Propuesta de Código Modelo de Cooperación Interjurisdiccional para
Iberoamérica [Ada Pellegrini Grinover, Brasil; Ricardo Perlingeiro Mendes da Silva, Brasil ; Abel Augusto
Zamorano, Panamá; Ángel Landoni Sosa, Uruguay; Carlos Ferreira da Silva, Portugal; Eduardo Véscovi, Uruguay;
Juan Antonio Robles Garzón, España; Luis Ernesto Vargas Silva, Colombia; Roberto Omar Berizonce, Argentina.
Texto aprobado en la Reunión presencial ocurrida el 15 de setiembre de 2007, en el Hotel Pestana, Salvador / Bahía,
en ocasión del XIII Congreso Mundial de Derecho Procesal de la Asociación Internacional de Derecho Procesal,
revisado el 15 de octubre de 2007 . Código aprobado en la Asamblea General del Instituto Iberoamericano de
Derecho Procesal, celebrada el 17 de octubre de 2008, por ocasión das XXI Jornadas Iberoamericanas de Derecho
Procesal, Lima, Perú. Disponible en: https://papers.ssrn.com/sol3/papers.cfm?abstract id=2250843. Consultado por
última vez el 06/04/2018.
54 Reflection paper to assist in the preparation of a convention on jurisdiction and recognition and enforcement of
foreign judgments in civil and commercial matters, preparado por Andrea Schulz, First Secretary, Hague Conference
on Private International Law-Enforcement of Judgments, Prel.Doc. N N 19, august 2002. En: http://www.hcch.net/upload/wop/jdgm_pd19e.pdf.

${ }_{55}$ En la introducción a los referidos principios, se señalaba: "The human community of the world lives in closer quarters today than in earlier times. International trade is at an all-time high and is increasing steadily; international investment and monetary flows increase apace; businesses from the developed countries establish themselves all over the globe directly or through subsidiaries; business people travel abroad as a matter of routine; ordinary citizens in increasing numbers live temporarily or permanently outside their native countries. As a consequence, there are positive and productive interactions among citizens of different nations in the form of increased commerce and wider possibilities for personal experience and development. There are also inevitable negative interactions, however, including increased social friction, legal controversy, and litigation." Joint American Law Institute/Unidroit Working Group on Principles and Rules of Transnational Civil Procedure, Draft Principles and Rules prepared by Professors G. Hazard, R. Stürner, M. Taruffo and A. Gidi, Rome, Study LXXVI - Doc. 7 (Original: English) May 2002.

56 Ley 29/2015, de 30 de julio. Disponible en: https://www.boe.es/diario boe/txt.php?id=BOE-A-2015-8564. (Consultada por última vez el 02/11/2017)

${ }^{57}$ En la misma orientación, el artículo 41 (4) señala: “Sólo serán susceptibles de reconocimiento y ejecución las medidas cautelares y provisionales, cuando su denegación suponga una vulneración de la tutela judicial efectiva, y siempre que se hubieran adoptado previa audiencia de la parte contraria." También el art. 54 (2) dispone "Podrá solicitarse la de adopción de medidas cautelares, con arreglo a las previsiones de la Ley de Enjuiciamiento Civil, que aseguren la efectividad de la tutela judicial que se pretenda."

${ }^{58}$ Nos referimos aquí a los enfoques básicos, descritos por Cappelletti y Garth, a través de los cuáles los países de cultura occidental han intentado reducir los obstáculos al acceso a la justicia. Tales enfoques, respondieron al creciente interés por este derecho, y habrían emergido como "olas", en secuencia cronológica, iniciadas a partir de 1965, conformando así el movimiento mundial para mejorar el acceso a la justicia. La primera ola del movimiento estuvo caracterizada por la implantación de sistemas de asistencia legal gratuita para los sectores más pobres, a raíz del despertar de una conciencia social que colocó la ayuda jurídica en la cumbre de las reformas legales. La segunda ola que describen se inicia inmediatamente después de que comienza la primera, y se enfoca en el problema de los intereses difusos y colectivos. La tercera ola está constituida por lo que los referidos autores denominaron el "enfoque de acceso a la justicia" y comprende un alcance mucho mayor que el pretendido en los anteriores. El enfoque de la tercera ola "se extiende a todas las instituciones y recursos, el personal y los procedimientos utilizados

Revista de Direito Brasileira | São Paulo, SP | v. 20 | n. 8 | p. 336-363 |Mai./Ago. 2018 
componente transnacional del acceso a la justicia, constituyéndose una "cuarta ola", de cambios y reformas. ${ }^{59}$ Esta viene marcada por la creciente ratificación de tratados internacionales sobre cooperación interjurisdiccional, ${ }^{60} \operatorname{los}$ aportes doctrinales sobre el acceso transnacional a la justicia, ${ }^{61}$ instrumentos de soft law, ${ }^{62}$ el "jugment project" de la Conferencia de La Haya, reformas legislativas y proyectos de reformas. ${ }^{63}$

\section{EL DERECHO INTERNACIONAL PRIVADO EN TIEMPOS DE GOBERNANZA GLOBAL}

El declive en la capacidad del Estado para incidir en la regulación de la conducta social, resulta determinante para entender el fenómeno de la gobernanza. Ya no es solo el Estado quien determina la política doméstica ni la internacional, pues se ha evidenciado que tales políticas son también determinadas e influenciadas por corporaciones transnacionales, organizaciones internacionales, asociaciones gremiales, otras ONGs, etc. ${ }^{64}$

Precisamente, una manera de definir la "gobernanza" es la de un fenómeno más comprehensivo de la idea de gobierno, que no solo abarca a las instituciones públicas, sino también subsume mecanismos informales, no gubernamentales, en los cuales las personas y organizaciones avanzan dentro de su ámbito de actuación, en la búsqueda se sus respectivos fines

para procesar y aun para prevenir disputas en las sociedades modernas." Cappelletti, Mauro y Garth, Bryant, El acceso a la justicia..., ob. cit., pp. 35-45.

${ }^{59}$ Esta expresión la hemos tomado de la ponencia dictada por la profesora Inés López, de la Universidad de Brasilia, en el marco del II Congreso de Processo Civil Internacional, en Vitória, Brasil, entre el 20 y el 22 de septiembre de 2017. Para la profesora, y nosotros coincidimos con ella, cabe hablar ya de una cuarta ola que viene precisamente caracterizada por las reformas encaminadas a facilitar el acceso transnacional a la justicia.

${ }^{60}$ Ochoa Muñoz, Javier, Desarrollo histórico de la cooperación jurídica internacional y desafíos actuales, ob. cit., pp. 34.

${ }^{61}$ Véase Fernándes Arroyo, Diego P., La tendance à la limitation de la compétence judiciaire à l'épreuve du droit d'accès à la justice, en AAVV, Mélanges Bernard Audit, Dalloz, París, 2014, pp. 285-306.Rábago Dorbecker, Miguel, El acceso a la justicia en casos de litigio internacional..., ob. cit.

${ }^{62}$ Son muchos los trabajos que se han venido desarrollando en el ámbito del soft law. Entre tales destacan los siguientes: 1.- Principios ALI-UNIDROIT del Proceso Civil Transnacional, disponibles en: http://www.unidroit.org/english/principles/civilprocedure/ali-unidroitprinciples-e.pdf. 2.- El Código Modelo para la Cooperación Interjurisdiccional para Iberoamérica del Instituto Iberoamericano de Derecho Procesal. Disponible en: http://www.ripj.com/art_jcos/art_jcos/num22/conclusiones/C\%C3\%B3digo\%20Modelo\%20de\%20Cooperaci\%C3\% B3n.pdf. 3.- El Protocolo Iberoamericano de Cooperación Judicial Internacional en 2014 por la Cumbre Judicial Iberoamericana. Disponible en: http://www.cumbrejudicial.org/c/document library/get file?uuid=0db452e9-450943cb-bf2e-629fa183db53\&groupId=10124. 4.- Los Principios ASADIP sobre el Acceso Transnacional a la Justicia (TRANSJUS), que serán comentados infra $x x x$.

${ }^{63}$ España con la Ley de cooperación jurídica internacional en materia civil del 30 de julio de 2015, que establece un robusto cuerpo de normas del proceso civil internacional desde una óptica de la cooperación más extensa, incluyendo la jurisdicción, la eficacia de sentencias extranjeras, información del derecho extranjero, además de los temas clásicos de la cooperación judicial internacional. En Brasil, destaca la Reforma del Código de Procedimiento Civil aprobada en diciembre de 2014. Véase al respecto: Klein Vieira, Luciane y Alvares Gaspar, Renata, Brasil: Habemus nuevo código procesal civil. Sus principales alteraciones en el derecho procesal internacional. En: https://cartasblogatorias.com/2015/04/21/brasil-habemus-nuevo-codigo-procesal-civil-sus-principales-alteracionesen-el-derecho-procesal-nternacional/. La Argentina cuenta con un nuevo Código Civil y Comercial de la Nación del 7 de octubre de 2014, el cual entró en vigencia en enero de 2016. Véase al respecto: Fernández Arroyo, Diego P., Argentina: Comentarios sobre el nuevo derecho internacional privado para la República Argentina. En: https://cartasblogatorias.com/2014/10/29/argentina-observaciones-al-nuevo-dipr-para-la-republica-argentina/. En Venezuela la Asamblea Nacional discute un proyecto de reforma del Código de Procedimiento Civil, que incorpora una regulación detallada de diversos aspectos de la cooperación jurídica internacional.

${ }^{64}$ Scotti, Luciana B., Los escenarios del Derecho Internacional Privado actual: Globalización, integración y multiculturalidad, en AAVV, Derecho internacional privado y derecho de la integración, Libro Homenaje a Roberto Ruiz Díaz Labrano, Asunción, CEDEP, 2013, pp. 147-168, esp. p. 155. Disponible también en: https://sociedip.files.wordpress.com/2013/12/los-escenarios-del-derecho-internacional-privado-actualglobalizacic3b3n-integracic3b3n-y-multiculturalidad-scotti.pdf.

Revista de Direito Brasileira | São Paulo, SP | v. 20 | n. 8 | p. 336-3363 |Mai./Ago. 2018 
e intereses, la satisfacción de sus necesidades y el cumplimiento de sus deseos. Es una noción que nace de las ciencias políticas para entender mejor las relaciones de poder que determinan la realidad social. Podría afirmarse también que se trata de un replanteamiento de las perspectivas de análisis que procura la formación de una teoría de gobierno más amplia, a fin de diseñar políticas públicas más apropiadas y eficientes.

Este enfoque cobra especial fuerza en el Derecho, cuando no se le concibe como una herramienta mecánica de control social y simple referente del orden y la paz, sino que se pretende que regule la actividad humana de manera eficiente, contribuyendo además a lograr el bienestar social. De manera que la idea también está asociada a la búsqueda de la eficiencia del Derecho, tratando de ampliar el enfoque de la realidad que pretende regular.

Obviamente, pues, estamos ante un concepto polisémico.

Horatia Miur Watt explica que el término "gobernanza", a pesar de que tiene otras implicaciones cuestionables, facilita el diálogo interdisciplinario a través de un vocabulario común para distintas ciencias sociales, al tiempo que permite desconectar la idea del Estado y el Derecho, así como reconocer el poder de los actores privados. ${ }^{65}$ La concepción "wesphaliana", estado centrista y privatista, sobre la cual se edificó el Derecho Internacional Privado, resulta hoy inconsecuente la nueva la realidad global. ${ }^{66}$

En el Derecho Internacional Privado se cuestiona la falta de respuesta que esta disciplina ha venido brindando a los problemas reales del mundo globalizado, mostrándose muy silenciosa ante la distribución cada vez más desigual de la riqueza y el poder en el mundo, y sin importar las injusticias que sufren los particulares en áreas como los mercados financieros, la contaminación del medio ambiente, las deudas soberanas, la confiscación de los recursos naturales, el uso y el mal uso de la ayuda al desarrollo, la migración de la población, y muchos más. ${ }^{67}$ Para Muir Watt, la explicación de esta situación parece estar en el desarrollo de una "epistemología del closet", 68 llevada a cabo bajo la égida de la separación liberal del Derecho y la política, y de la esfera pública de la privada; lo cual se ha traducido en "la negativa a ver que dar rienda suelta a poderosos intereses privados en nombre de la autonomía individual y permitirles a éstos que puedan acceder a la autoridad del mercado, era construir los fundamentos jurídicos de un imperio informal y generar grandes agujeros en la gobernanza global.",69

Ante este panorama, el rol del Derecho Internacional Privado resulta fundamental. Está llamado a constituirse en un vector de la gobernanza global para ayudar a colmar los "agujeros negros" de la misma, y resulta obvio que todavía le queda un trecho considerable para desempeñar satisfactoriamente esa función. ${ }^{70}$ Muir Watt, apunta que es tiempo ya de sacar del armario al Derecho Internacional Privado, y excavar los instrumentos con los cuales, desde su propio ámbito, puede impactar sobre el balance del poder informal en la economía global. Adoptar una perspectiva planetaria significa alcanzar más allá del cisma, conectándose con las políticas del Derecho Internacional Público, y mientras tanto debe contribuir con su particular

\footnotetext{
${ }^{65}$ Muir Watt, Horatia, Private International Law Beyond the Schism, pp. 3-4 (Nota de pie Nro. 8). Disponible en: https://spire.sciencespo.fr/hdl:/2441/53r60a8s3kup1vc9k70p9ikj1/resources/hmw-pilagg-paper-final.pdf. Consultado por última vez el 06/04/2018.

${ }^{66}$ Véase, Scotti, Luciana B., Los escenarios del derecho internacional privado actual..., ob. cit., p. 148.

${ }^{67}$ Véase, Wai, Robert, Transnational Liftoff And Juridical Touchdown: The Regulatory Function Of Private International Law In An Era Of Globalization, Columbia Journal of Transnational Law. Vol. 40, Tom. 2, 2002, pp. 209-274. Disponible

en: http://digitalcommons.osgoode.yorku.ca/cgi/viewcontent.cgi?article=1686\&context=scholarly_works. Consultado por última vez el 03/04/2018.

${ }^{68}$ Toma la expresión del libro de Eve Kosofsky Sedgewick, "Epistemology of the Closet", referido a las conductas sexuales del ser humano. Muir Watt, Horatia, Private International Law Beyond the Schism, ob. cit., p. 9 (Nota de pie Nro. 32).

${ }^{69}$ Muir Watt, Horatia, Private International Law as Global Governance: Beyond the Schism, from Closet to Planet, p. 1. Disponible en: http://works.bepress.com/horatia muir-watt/1. Consultado por última vez el 03/04/2018.

${ }^{70}$ Fernández Arroyo, Diego, El Derecho internacional privado en el diván..., ob cit., p. 30.
} 
"savoir-faire"("know-how") adquirido durante muchos siglos en el reconocimiento de la diversidad y el manejo responsable del pluralismo. ${ }^{71}$

El divorcio entre lo privado lo público, lo local y lo internacional, trae como resultado un conjunto de vacíos en la gobernanza global, entre los cuales se desenvuelve un imperio de poder privado, sin los controles que permitan asegurar la justicia y el bienestar global. Estos intereses privados funcionan a veces en detrimento del planeta, en términos de la distribución y protección adecuadas de los recursos ecológicos y económicos. ${ }^{72}$

Robert Wai afirma que el Derecho Internacional Privado siempre ha servido como interfaz entre lo local y lo global, permitiendo que las culturas nacionales ocupen un lugar en el gobierno de las situaciones, más allá de sus propios límites territoriales. Tal función de mediación del Derecho Internacional Privado, entre las distintas fuentes, locales y globales, públicas y privadas, debe ser recordada y reinventada en un mundo en el que la falta de esa mediación y la falta de una debida articulación entre dichas fuentes, puede ser una de las principales causas sus malestares. $^{73}$

Las herramientas del Derecho Internacional Privado podrían permitir establecer una suerte dimensión disciplinaria con respecto a la acción estatal y la privada. Las reglas jurisdiccionales y de conflictos de leyes, por ejemplo, podrían dar voz a los sectores más débiles, forzando a los actores poderosos no estatales a un "aterrizaje jurisdiccional", extendiendo su responsabilidad social y ambiental, para que coincida con su esfera de influencia. ${ }^{74}$

\section{GOBERNANZA JUDICIAL TRANSNACIONAL}

Explica David Kennedy que entre los principales esfuerzos por replantear y descubrir la gobernanza global destacan tres enfoques emblemáticos que pueden verse como "los padres de todas las reinvenciones en el campo de la gobernanza global". ${ }^{75}$ El proyecto final constituye de algún modo una reacción y una síntesis depurada de los anteriores. Sus orígenes se ubican en la Universidad de Yale, con la persona de Harold Koh, y en Harvard, con varios profesores como Detlev F. Vagts, Abram Chayes, Antonia Handler Chayes, Anne-Marie Slaughter-Burley y Henry Steiner. La llave de la gobernanza global se encontraba en el derecho nacional, en las cortes nacionales y los procedimientos que distribuyen la autoridad entre ellas. El enfoque se desplazó de la búsqueda por mantener la paz, estructurar la coexistencia y facilitar los proyectos de cooperación, hacia la resolución de disputas y la corrección de la voluntad política. ${ }^{76}$ Aunque este enfoque sea susceptible de cuestionamientos válidos, hoy parece indiscutible el rol determinante que pueden tener los tribunales locales en la confección de la gobernanza global.

Advierte Eyal Benvenisti que los Estados producen ordenaciones unilaterales de la gobernanza global, no sólo a través de sus legislaciones sustantivas, que desde tiempo atrás desbordan el ámbito territorial interno pretendiendo regular la realidad transnacional, sino que también lo hacen al extender la jurisdicción de sus tribunales sobre eventos foráneos. Este autor destaca el paradigmático caso del Alien Torts Statute de los EEUU, que a pesar de haberse restringido su alcance a raíz de la decisión de la Corte Suprema de Justicia en el caso

\footnotetext{
${ }^{71}$ Muir Watt, Horatia, Private International Law as Global Governance: Beyond the Schize, from Closet to Planet, ob. cit., p. 1

${ }^{72}$ Ibid, p. 13 y sig.

${ }^{73}$ Wai, Robert, Transnational Liftoff And Juridical Touchdown..., ob. cit., pp. Muir Watt, Horatia, Private International Law as Global Governance: Beyond the Schize, from Closet to Planet, ob. cit., p. 34.

${ }^{74} \mathrm{Ibid}$, p. 50. Wai, Robert, Transnational Liftoff And Juridical Touchdown ..., ob. cit., pp. 265-268.

${ }^{75}$ Kennedy, David, El misterio de la gobernanza global, Trad. M.A. Prada Uribe, Revista de Derecho Público, No 24 , 2010, $\quad$ pp. $1-30, \quad$ esp, $\quad$ p. $13-14$. http://www.law.harvard.edu/faculty/dkennedy/publications/el\%20misterio\%20de\%201a\%20gobern 2010062311371 9.pdf. Consultado por última vez el 03/02/2018.

${ }^{76}$ Ibid., p. 13-14.
}

Revista de Direito Brasileira | São Paulo, SP | v. 20 | n. 8 | p. 336-3363 |Mai./Ago. 2018 
Kiobel,conserva importantes alcances extraterritoriales. Además, opciones como esta se mantienen en varios Estados europeos, así como en Estados suramericanos como Chile. ${ }^{77}$

El rol de los tribunales locales en la articulación de la gobernanza global es un debate emergente, que ha generado atención, especialmente en la doctrina estadounidense y europea. Hannah Buxbaum, profesora de la Universidad de Indiana, comenta que los litigios transnacionales ante tribunales locales se consideran como herramientas para mejorar el cumplimiento global del Derecho Internacional, contribuyendo además a reducir la ausencia de mecanismos de coerción internaciones. Sin embargo, estos casos también dan a los tribunales nacionales un papel en el proceso transnacional de articular y defender normas globales en beneficio de la comunidad internacional. ${ }^{78}$

Christopher Whytock, profesor de Derecho y Ciencias políticas de la Universidad de California,es uno de los principales promotores de la idea de resaltar el rol de los órganos judiciales en la gobernanza global, acuñando la expresión"gobernanza judicial transnacional ("transnational judicial governance"). ${ }^{79}$ Advierte que en la actualidad las decisiones judiciales de los Estados, tienden a ser frecuentemente noticias mundiales, pero su rol se extiende mucho más allá de los titulares noticiosos. Decisiones aparentemente de rutina sobre cuestiones como la jurisdicción personal, litispendencia, forum non conveniens, elección de la ley, las antisuit injuctions, arbitraje, eficacia de sentencias extranjeras y tratados internacionales, entre otras, tienen implicaciones para la gobernanza global. Los académicos del Derecho tienden a separar este tipo de aspectos dentro de las distintas disciplinas jurídicas, tales como el Derecho Procesal Civil, Derecho Internacional Público, Derecho Internacional Privado, Arbitraje, relaciones internacionales, etc. Pero al hacer esto se pierde el cuadro más grande: para bien o para mal, los tribunales locales están inmersos y envueltos en la regulación de la actividad transnacional. ${ }^{80}$

Sobre esta base observa que, al decidir asuntos típicos de la litigación transnacional, los tribunales domésticos abordan dos funciones básicas de la gobernanza global: $i$.-Determinan y asignan autoridad de gobernanza entre los estados, entre las instituciones nacionales e internacionales, y entre las instituciones públicas y privadas; y ii.- determinan los derechos y obligaciones de los actores transnacionales. Estas funciones se corresponden con dos interrogantes fundamentales de la gobernanza: $i$.- ¿Quién gobierna? (Who governs?) y ii.- ¿qué le toca a cada quien? (who gets what?), en otras palabras, cómo se distribuyen las cosas y las riquezas. Los tribunales locales se convierten así en gobernantes globales. ${ }^{81}$

Pero las decisiones de los tribunales no solo tienen el correspondiente efecto vinculante sobre las partes del litigio, sino que tienen posiblemente mayor importancia por su influencia más allá de las fronteras y más allá de las partes. La decisiones envían una señal a los demás actores, anunciando que el tribunal tomará una decisión similar en virtud circunstancias similares en el futuro. ${ }^{82}$ Se produce un "efecto de sombra indirecto" sobre el comportamiento estratégico de actores transnacionales en general: la "sombra transnacional del Derecho". ${ }^{83}$

\footnotetext{
${ }^{77}$ Benvenisti, Eyal, The Law of Global Governance, Recueil des Courses, Vol. 368, 2014, p. 101.

${ }^{78}$ Buxbaum, Hannah, Transnational Regulatory Litigation, Articles by Maurer Faculty, Paper 290, 2006, pp. 252317, esp. p. 254. Disponible en en: http://www.repository.law.indiana.edu/facpub/290. Consultado por última vez el $01 / 03 / 2018$.

${ }^{79}$ Christopher A. Whytock, Domestic Courts and Global Governance: The Politics of Private International Law, Dissertation submitted in partial fulfillment of the requirements for the degree of Doctor of Philosophy in the Department of Political Science in the Graduate School of Duke University, 2007, p. 6 y sig..Disponible: en: https://dukespace.lib.duke.edu/dspace/bitstream/handle/10161/452/D_Whytock_Christopher_a_200712.pdf;sequence $=$. Consultado por última vez el 06/04/2018.

${ }^{80}$ Whytock, Christopher A, Domestic Courts and Global Governance, Tulane Law Review, Vol. 84, No. 67, 2009, pp. 67-123, esp. p. 69. Disponible en: http://ssrn.com/abstract=923907. Consultado por última vez el 06/04/2018.

${ }^{81}$ Ibid., p. 70.

${ }^{82}$ Ibid., p. 99.

${ }^{83}$ Ibid., p.97-99. El autor se vale de una metáfora tomada de Robert Mnookin y Lewis Kornhauser, conocida como la "sombra del Derecho" ("shadow of the law") empleada para representar la influencia de los tribunales con Revista de Direito Brasileira | São Paulo, SP | v. 20 | n. 8 | p. 336-363 |Mai./Ago. 2018
} 
De hecho, observa Whytoc, que en algunos casos los demandantes están más interesados en la posibilidad de establecer una estrategia, que en los efectos directos de los litigios respectivos. ${ }^{84}$ En este sentido, se adhiere a la afirmación de Harold Koh, en cuanto a que los jueces pueden pensar que están resolviendo solo una disputa en particular, pero en realidad también están declarando (o negando) normas internacionales que los litigantes trasladan a otros foros para su uso en la negociación. ${ }^{85}$

De modo que las decisiones de los tribunales nacionales afectan la conducta de los actores transnacionales, especialmente sus comportamientos estratégicos. Así, las sentencias y decisiones judiciales, en general, pueden aumentar o reducir el bienestar económico global; y pueden obstaculizar o brindar apoyo a otras instituciones de gobernanza global, incluidas instituciones internacionales, como los tribunales internacionales y el propio Derecho Internacional y, también, instituciones privadas, como la contratación transnacional y el arbitraje transnacional.

\section{1. ¿Quién gobierna? Determinación judicial de la autoridad de gobernanza}

En el ámbito internacional se presentan también los tres tipos esenciales de autoridad: $i$.la autoridad de juzgar, que comprende el poder de interpretar y aplicar las reglas; ii.- la autoridad normativa, que comprende el poder de dictar las normas; y, iii.- la autoridad ejecutiva, que comprende el poder de constreñir el cumplimiento de las normas. En este sentido, los tribunales locales no solo determinan la autoridad entre los diferentes Estados, sino también entre entes locales e internacionales, y entre instituciones públicas y privadas. De este modo, responden a tres variantes de la interrogante fundamental de ¿Quién gobierna?: i.- ¿Quién juzga? (Who adjudicates?); ii.- ¿Quién crea las normas? (Who prescribes?), y iii.- ¿Quién hace cumplir las normas? (Who enforces?). Y lo hacen con respecto a tres dimensiones de referencia: i.- la doméstica-extranjera, ii.- domestica-internacional y, iii.- pública-privada. ${ }^{86}$

En la dimensión doméstica-extranjera, los tribunales locales determinan la autoridad para juzgar cuando deciden acerca de su propia jurisdicción, frente la de tribunales de Estados extranjeros. Esta determinación de la autoridad para juzgar, también se deduce, indirectamente, de las decisiones relativas a la eficacia de sentencias extranjeras. Los tribunales también pueden tomar decisiones que afecten la asignación de la autoridad normativa, respondiendo así al "quién crea la norma", variante de la pregunta fundamental sobre "quién gobierna". Así sucede cuando toman alguna determinación sobre conflictos de leyes estatales. ${ }^{87}$

Del mismo modo los tribunales nacionales intervienen en la fijación de la autoridad de gobernanza entre las instituciones nacionales e internacionales (dimensión domésticainternacional). A veces deben responder la interrogante sobre "quién juzga". Por ejemplo, cuando tanto un tribunal nacional como un tribunal internacional parecen tener jurisdicción sobre una disputa particular, ¿Cuál debe en definitiva el que debe conocer el asunto? Los tribunales estadounidenses, por ejemplo, han aplicado la doctrina forum non conveniens para elegir entre la afirmación de la jurisdicción interna y la declinación a la autoridad jurisdiccional de un tribunal internacional. ${ }^{88}$ Además, los conflictos de leyes, no solamente pueden envolver conflictos entre

competencia en divorcios sobre la conducta de las parejas en esos procesos, fuera del recinto del tribunal. Se refiere al trabajo de Robert H. Mnookin y Lewis Kornhauser, Bargaining in the Shadow of the Law: The Case of Divorce, 88 YALE L.J. 1979.

${ }^{84}$ Ibid., p. 100.

${ }^{85}$ Hongju Koh, Harold, Transnational Public Law Litigation, Yale Law Journal, Vo. 100, 199, pp. 2347-2402, esp. p. 2395. Disponible en: http://digitalcommons.law.yale.edu/cgi/viewcontent.cgi?article=2944\&context=fss_papers.

${ }^{86}$ Whytock, Christopher A, Domestic Courts and Global Governance, ob. cit. p. 75-76.

${ }^{87}$ Ibid., p. 80.

${ }^{88}$ En este sentido cita los siguientes precedentes: Nemariam v. República Democrática Federal de Etiopía, 15 F.3d 390, 395 (D.C. Cir. 2003) (se revirtió la decisión de un tribunal de instancia que había declinado su jurisdicción Revista de Direito Brasileira | São Paulo, SP | v. 20 | n. 8 | p. 336-3363 |Mai./Ago. 2018 
legislaciones de diferentes Estados, sino también entre la legislación interna de un Estado y una normativa internacional. Por otra parte, este tipo de determinación también se plantea cuando se solicita el reconocimiento o ejecución de una decisión dictada por un órgano jurisdiccional internacional. A la postre, suelen ser los tribunales locales los que determinan la autoridad de la sentencia o decisión del órgano internacional. ${ }^{89}$

Finalmente, los tribunales locales también determinan la autoridad de gobernanza entre el Estado y los actores no estatales (dimensión doméstica-privada). Por ejemplo, al reconocer y hacer valer un acuerdo arbitral, los tribunales están atribuyendo autoridad para juzgar a una institución arbitral, en consecuencia, declinando su poder ante una entidad privada. Pero al negarse a dar validez a un acuerdo arbitral y permitir que el litigio judicial continúe, el tribunal está asignando la autoridad de juzgar en la institución pública. Lo mismo ocurre cuando se reconoce o no un laudo arbitral. También determinan la autoridad normativa entre los actores públicos y privados. Cuando dan valor a la lex mercatoria en virtud de la propia escogencia de las partes o por cualquier otra razón o, en definitiva, cuando aplican o dejan de aplican cualquier fuente normativa de origen no estatal, están determinando quién crea la norma, es decir, le están atribuyendo autoridad normativa al actor no estatal. ${ }^{90}$

Las respuestas a estas variantes de la pregunta fundamental sobre "quién gobierna" rara vez son obvias. Debido a que la actividad transnacional, por definición, tiene conexiones con más de un Estado, más de un Estado puede tener una base para ejercer legítimamente su autoridad para gobernarla. Con los actores privados reivindicando cada vez más la autoridad para gobernar la actividad transnacional, tradicionalmente gobernada por el Estado, la asignación de la autoridad de gobierno entre las instituciones públicas y privadas también plantea serios desafíos. Y con la expansión del Derecho Internacional y los tribunales internacionales, hay decisiones igualmente difíciles de tomar, sobre si estos o las instituciones domésticas, deberían gobernar una actividad transnacional particular. Como resultado, concluye Whytoc, es probable que la función jurisdiccional de los tribunales nacionales en la gobernanza global sea cada vez más importante. ${ }^{91}$

\section{2. ¿Qué le toca a cada quién? Determinación de la distribución de los bienes y la riqueza}

¿Quién disfruta de qué derechos y quién tiene qué obligaciones en la actividad transnacional? Los tribunales nacionales contribuyen a responder esta pregunta al determinar los derechos y obligaciones que corresponden a los actores transnacionales con respecto a sus obligaciones entre sí. ${ }^{92}$ Esta es la función substantiva en la gobernanza global de los tribunales locales.

Pero la determinación de los derechos y obligaciones es más que una función de resolución de controversias. Cuando la resolución de controversias se basa en normas, se convierte también en una forma de regulación. Desde la perspectiva de la ciencia política, los tribunales son importantes no solo porque resuelven controversias, sino también porque contribuyen a determinar la distribución de los recursos de una sociedad.

Whytoc observa cómo la doctrina, en especial la norteamericana ha venido estudiando y destacando, el rol que juegan los tribunales dentro de su ámbito nacional en la distribución de los bienes y las riquezas entre la sociedad.Pero al mismo tiempo advierte que, ni los académicos del

sobre la base del fórum non conveniens en favor de Comisión de Reclamaciones de Etiopía/Eritrea); asunto Assicurazioni Generali S.P.A. Holocaust Ins. Litig., 228 F. Supp. 2d 348 (S.D.N.Y. 2002) (en el que se denegó la solicitud de declaratoria del fórum non conveniens desestimar a favor de los procedimientos ante la International Commission on Holocaust Era Insurance Claims). Ibid., p. 84.

${ }^{89}$ Ibid., 86-88.

${ }^{90}$ Ibid., p. 89-90.

${ }^{91}$ Ibid., p. 89-90

${ }^{92}$ Advierte el autor que no se trata de desconocer el rol que también juegan las fuentes formales del Derecho como los tratados, las constituciones y las leyes, sino simplemente de resaltar la importancia que en definitiva tiene la actividad jurisdiccional en la determinación de los derechos y obligaciones. Ibid., p. 91 y nota 93. 
Derecho ni los científicos políticos, han explorado sistemáticamente las implicaciones de esta función judicial para la gobernanza global. ${ }^{93}$

En el contexto específico de la litigación privada transnacional, Whytock cuestiona el énfasis usualmente planteado respecto del Derecho público, incluyendo las normas sobre derechos humanos, lo cual genera el riesgo de oscurecer el papel del Derecho privado en la gobernanza global. El Derecho privado incluye las normas sobre reparación de daños por hechos ilícitos, sobre contratos, sobre propiedad, entre otros aspectos, y cumple un rol tan determinante en la gobernanza como el del Derecho público. En efecto, las normas de Derecho privado relativas a la propiedad y los contratos asignan y distribuyen la mayor parte de los recursos económicos en una sociedad capitalista. Del mismo modo, en el trasfondo del Derecho privado se encuentran políticas orientadas al bienestar general, en el sentido de que se procuran justas compensaciones de daños, correcciones de fallas del mercado, así como disuadir a los actores de la realización de actividades indeseables para la sociedad.

Estos elementos, entre otros, deben llamar la atención sobre la importancia de la litigación privada la función substantiva de la gobernanza global.

\section{BIENESTAR GLOBAL Y GOBERNANZA JUDICIAL TRANSNACIONAL}

Dada la complejidad de las interacciones en el contexto global, así como las implicaciones económicas de las mismas, resulta difícil establecer las orientaciones específicas que deberían tomar las leyes y los tribunales en su aplicación.

Existen argumentos válidos desde el punto de vista político para sostener que los tribunales locales no están en una posición adecuada institucionalmente para dirimir asuntos internacionales, pero ante la insuficiencia de otras instituciones de gobernanza internacionales, intergubernamentales o privadas, los tribunales locales pueden desempeñar un rol significativo llenando algunas de las lagunas. ${ }^{94}$

Por ejemplo, en materia de responsabilidad por hechos ilícitos, para autores como Muir Watt, el bienestar global apunta a las soluciones jurídicas más favorables a las víctimas. Precisamente observa que la doctrina del fórum non conveniens y la aplicación de la lex loci delicti constituyen a veces situaciones de importancia global que son particularmente preocupantes, en tanto que se constituyen en herramientas para limitar la responsabilidad social de las corporaciones, aumentan los riesgos ambientales y afectan injustificadamente a los países menos desarrollados. 95

Whytock, siguiendo a otros autores, defiende la orientación opuesta. En este sentido, cita a Michael Whincop y Mary Keyes, en un trabajo con prefacio de Richard Postner, quienes sugieren que mediante la asignación de la autoridad de juzgar a los foros con costos de litigación más bajos, los tribunales nacionales pueden mejorar la eficiencia global. ${ }^{96}$ En el mismo sentido, cita Alan Sykes, para quien la asignación judicial de la autoridad de juzgar debe entenderse como una cuestión de comercio e inversión. Las demandas en tribunales estadounidenses contra empresas estadounidenses que surgen de actividades que ocurren fuera de los EEUU, pueden conducir a la aplicación discriminatoria de normas de responsabilidad más estrictas al comportamiento de esas empresas. Sykes se refiere específicamente a las demandas de víctimas

\footnotetext{
${ }^{93}$ Ibid, p. 91.

${ }^{94}$ Whytock, Christopher A., Transnational Judicial Governance, St. John's Journal of International \& Comparative Law, Vol. 2, 2012, pp 55-68, esp. p. 67. Disponible en: https://scholarship.law.uci.edu/cgi/viewcontent.cgi?article=1083\&context=faculty_scholarship. Consultado por última vez, el 18/03/2018. Buxbaum, Hannah, Transnational Regulatory Litigation, ob. cit., p, 255, 271.

${ }^{95}$ Horatia Muir Watt, Private International Law Beyond the Schism, ob. cit., pp. 43.

${ }^{96}$ Se refiere al trabajo de Whincop, Michael J. y Keyes, Mary, Policy and Pragmatism in the Conflict of Laws, Ashgate, Burlington, Vt., 2001. Véase, Whytock, Christopher A., Domestic Courts and Global Governance, ob. cit., pp. 101.
} 
de actividades que se llevan a cabo en países en vías de desarrollo.Para él, esta discriminación causaría pérdidas al bienestar general en la medida en que las empresas menos eficientes sujetas a una responsabilidad menor, pueden desplazar a las empresas más eficientes y sujetas a una mayor responsabilidad. Sykes sostiene que los tribunales de los EEUU tendrían el poder de reducir ese perjuicio al bienestar general, limitando el acceso a la jurisdicción y a la legislación estadounidense a los litigantes foráneos en materia de daños por hechos ilícitos ocurridos fuera de los EEUU y remitiéndolos a la jurisdicción y la ley en que se produjo el daño. ${ }^{97}$

Hannah Buxbaum, por otra parte, sostiene que la litigación transnacional sobre regulaciones locales (transnational regulatory litigation) ante tribunales estadounidenses, en circunstancias adecuadas, puede permitir a esos tribunales participar en la implementación de estrategias regulatorias efectivas para los mercados. ${ }^{98}$ Los tribunales locales pueden movilizar recursos judiciales disponibles para abordar los desafíos del bienestar económico global, al igual que los desafíos en áreas tales como los derechos humanos en el orden global. La consolidación de los sistemas de litigación internacional, mejoraría la eficiencia procesal global. ${ }^{99}$ Sin embargo, la misma autora advierte que, en la medida en que estos litigios se llevan a cabo abrumadoramente en los tribunales de los EEUU, se corre el riego que funcionen como un instrumento de hegemonía. ${ }^{100}$ Los EEUU junto a Inglaterra han sido los foros principales de litigios transnacionales y sus leyes sustantivas se aplican tradicionalmente a las disputas transnacionales. La impresión general parece ser que el sistema de litigio transnacional es unipolar, o quizás bipolar. Esto implicaría que los Estados Unidos e Inglaterra se encuentran entre los participantes más influyentes de la gobernanza judicial transnacional. Sin embargo, algunas tendencias parecen indicar que ya otros países han comenzado a jugar un rol muy relevante en el sistema de litigios transnacionales, por lo que algunos comienzan a vislumbrar una gobernanza judicial multipolar. ${ }^{101}$

Ahora bien, las dificultades en la precisión de las orientaciones más adecuadas, específicamente en torno a los aspectos propios del proceso civil transnacional, plantean un doble desafío: $i$.- ofrecer una regulación que armonice los valores de propios de la gobernanza global entre sí, y ii.- ofrecer un sistema que coordine estos valores con los relativos a los derechos particulares, en especial el acceso a la justicia. ${ }^{102}$ No se trata de valores que sean necesariamente excluyentes; pueden coincidir e incluirse mutuamente.

La protección de los derechos particulares en determinados casos puede contribuir con los valores de la gobernanza, y algunos valores de la gobernanza pueden beneficiar los derechos de las partes litigantes. Pero también estos valores pueden encontrar puntos de conflicto, por lo que no siempre es posible maximizarlos simultánea y mutuamente en un mismo sistema. Esto significa que los diferentes enfoques en el proceso civil transnacional pueden implicar diferentes compensaciones entre los valores de gobernanza y los derechos particulares. Tales valores se componen de variables de muy distinta naturaleza. Los valores de gobernanza se refieren esencialmente a políticas que facilitan, orientan o restringen las actividades de la colectividad y

\footnotetext{
${ }^{97}$ Sykes, Alan O., Transnational Forum Shopping as a Trade and Investment Issue, Journal of Legal Studies, Vol. 37, 2008, p. 1. Disponible en: https://www.law.virginia.edu/pdf/olin/0708/sykes.pdf. Consultado por última vez el $04 / 04 / 2018$

${ }^{98}$ Buxbaum, Buxbaum, Hannah, Transnational Regulatory Litigation, ob. cit., p. 316.

${ }^{99}$ Ibid., 272, 304-305.

${ }^{100}$ Ibid., p. 255.

${ }^{101}$ Una tendencia significativa en el cambio hacia una gobernanza judicial multipolar, viene determinada por un importante repunte de solicitudes de eficacia de sentencias extranjeras en los EEUU. El aumento de litigios internacionales fuera de los EEUU, probablemente sea la causa principal de este repunte. Véase, Quintanilla, Marcus S. y Whytock, Christopher A., The New Multipolarity in Transnational Litigation: Foreign Courts, Foreign Judgments, and Foreign Law, Southwestern Journal of International Law, Vol.18, 2011, pp. 31-49, esp. pp. 35-37.

102 Whytock, Christopher A., Faith and Scepticism in Private International Law: Trust, Governance, Politics, and Foreign Judgments, Erasmus Law Review, No. 3, Noviembre, 2014, pp. 113-123, esp. p. 120. Disponible en: http://ssrn.com/abstract=2549847. Consultado por última vez el 04/04/2018.
}

Revista de Direito Brasileira | São Paulo, SP | v. 20 | n. 8 | p. 336-363 |Mai./Ago. 2018 
persiguen un interés colectivo, por lo que tienen implicaciones que van más allá de las partes litigantes. ${ }^{103}$ Asimismo, intereses no comerciales como la protección de los derechos humanos, la protección de la niñez, el medio ambiente, los derechos de los consumidores, pueden verse en conflicto con los intereses comerciales. ${ }^{104}$ Además, los propios intereses comerciales pueden también diferir según la nacionalidad o actividad particular de los actores, o incluso, según la situación específica en que se encuentren estos en un determinado litigio.

Se necesitaría alguna fórmula de balance para determinar el equilibrio entre los intereses comerciales y los no comerciales. En esta materia se carece suficientes datos estadísticos y de investigaciones cuantitativas. ${ }^{105}$ Se trata de un escenario de extrema incertidumbre.

Sin embargo, a pesar de las dificultades referidas, parece haber cierta concurrencia de factores en favor de un sistema de cooperación jurídica internacional, integral y eficiente. Lógicamente, en un mundo globalizado económica y socialmente, en el que los actores privados detentan poderes antes insospechados, parece aconsejable rescatar los mecanismos a través de los cuáles los Estados pueden controlar, dentro de los parámetros admisibles, las actividades humanas. ${ }^{106}$ Esta parece ser una de las herramientas más efectivas con que la cuentan los Estados y la sociedad global para controlar las actividades de los actores transnacionales.

En general, puede considerarse que un sistema de seguridad jurídica global favorece el bienestar económico del planeta. ${ }^{107}$ En este sentido, la Conferencia de La Haya ha expresado en su Reporte Explicativo Preliminar sobre el Anteproyecto de Convenio de Sentencias Extranjeras, lo siguiente: "Este proyecto de convención tiene como objetivo principal la promoción del comercio internacional, la inversión y la movilidad a través de una mayor cooperación judicial. Dicha cooperación mejorará el acceso a la justicia y reducirá los costos y riesgos asociados con las transacciones transfronterizas..."108

Además, no debe dejarse de considerar que la protección de los derechos humanos es también un importante valor de la gobernanza global. ${ }^{109}$ Vale tener en cuenta que en el mapa del Derecho Internacional Público actual, los derechos humanos son oponibles esencialmente a los Estados, dado que no existen mecanismos propiamente internacionales para reclamar frente a actores privados las responsabilidades derivadas de sus violaciones. Como resultado, observa Hans van Loon, las acciones legales contra empresas transnacionales supuestamente responsables de daños ambientales y de violaciones de derechos humanos, no pueden presentarse ante

\footnotetext{
${ }^{103}$ Ibid., 120-121.

${ }^{104}$ Perez, Antonio F., The International Recognition of Judgments: The Debate between Private and Public Law Solutions, Berkeley Journal of International Law, Volume 19, 2001, pp. 44-89, esp. p. 58. Disponible en: https://scholarship.law.berkeley.edu/cgi/viewcontent.cgi?article=1198\&context=bjil. Consultado por última vez el 04/04/2018.

${ }^{105}$ La falta de información estadística suficiente en esta materia ha sido advertida por diversos autores. Véase, Zeynalova, Yuliya, The Law on Recognition and Enforcement of Foreign Judgments: Is It Broken and How Do We Fix It?, Berkeley Journal of International Law, Nro. 31, 2013, 150-205, pp. esp.152.

Available at: http://scholarship.law.berkeley.edu/bjil/vol31/iss1/4. Antonio F. Perez, The International Recognition of Judgments..., ob. cit., p. 53,68. Strong, S.I., Recognition and Enforcement of Foreign Judgments in U.S. Courts: Problems and Possibilities, Review of Litigation __ (forthcoming 2014), No. 33; University of Missouri School of Law Legal Studies Research Paper No. 2013-18, p., 93, Nota de pie Nro. 496. Disponible en: http://ssrn.com/abstract=2313855. Consultados por última vez el 04/04/2018.

${ }^{106}$ Véase, Scotti, Luciana B., Los escenarios del derecho internacional privado actual, ob. cit., p. 813.

${ }^{107}$ Goicoechea, Ignacio, Nuevos Desarrollos en la Cooperación Jurídica Internacional en Materia Civil y Comercial, ob. cit., pp. 129-130. Disponible en: http://www.revistastpr.com/index.php/rstpr/article/view/19. Consultado por última vez el 04/04/2018.

108 “...8. En un mundo globalizado e interconectado, con un movimiento cada vez mayor a través de las fronteras de las personas, la información y los activos, la importancia práctica de alcanzar estos objetivos es evidente.” Traducción libre delJudgments Convention: Preliminary Explanatory Report, preparado por Francisco J. Garcimartín Alférez y Geneviève Saumier, del 7 de octubre de 2017. Disponible en: https://assets.hcch.net/docs/e1b5b4de-d68e41f0-9ac4-6492345a5b0d.pdf. Consultado por última vez el 04/04/2018.

${ }^{109}$ Kennedy, David, El misterio de la gobernanza global..., ob. cit., p. 12-13, 29.
}

Revista de Direito Brasileira | São Paulo, SP | v. 20 | n. 8 | p. 336-3363 |Mai./Ago. 2018 
tribunales internacionales, sino que deben incoarse a través de demandas civiles ante tribunales nacionales. ${ }^{110}$ Incluso, el Derecho Internacional Público no facilita a los particulares los reclamos internacionales por violaciones a los derechos humanos cometidas por actores estatales.

Con lo que las herramientas del Derecho Internacional Privado se convierten también en una de las pocas que tienen los particulares para obtener alguna tutela jurídica trasnacional respecto de las violaciones de derechos humanos cometidas por actores estatales. Esta suerte de vacío del Derecho Internacional Público, puede ser solventado en gran medida por el Derecho Internacional Privado, precisamente a través de las fórmulas de jurisdicción, ley aplicable, cooperación judicial y de eficacia de sentencias extranjeras, extendiendo al ámbito transnacional la protección de los derechos humanos frente a actores no estatales.

En un mundo tan globalizado las políticas estatales plasmadas en los ordenamientos jurídicos locales, así como en las propias normas internacionales, verían significativamente mermada su efectividad sin un esquema adecuado de cooperación interjurisdiccional entre los Estados que permita extender esa parte de las funciones estatales al ámbito transnacional. Los equilibrios sociales y económicos que los Estados procuran alcanzar, la protección de los consumidores, los trabajadores, los niños, los ancianos y personas vulnerables en general, así como del medio ambiente, requieren el concierto de la comunidad internacional, más allá de las ramas ejecutivas de los gobiernos. La coordinación debe plantearse en casi todas las funciones gubernamentales, incluyendo también la legislativa y la judicial. ${ }^{111}$

Pensamos que, en líneas generales, un mejor sistema de acceso transnacional a la justicia tiende a favorecer a las personas comunes, así como a las pequeñas y medianas empresas, los cuales se ven en mayores dificultades para afrontar las demoras y los costos que implican los procesos de reconocimiento y ejecución. Por otro lado, como también explica Strong, a medida que las economías y las sociedades se han globalizado, una serie de políticas y prácticas que alguna vez parecieron proteger a las partes e intereses de los EEUU, han experimentado una suerte de regresión. Como resultado, la comunidad empresarial de ese país está reconociendo que un sistema predecible y uniforme de reconocimiento y ejecución de sentencias extranjeras, resulta ventajoso para las empresas y personas de los EEUU. ${ }^{112}$ La propia Cámara de Comercio Internacional, ha emitido pronunciamientos llamando a los Estados a ratificar el Convenio de la Haya de 2005 sobre Acuerdos de Elección de Foro, que busca asegurar la eficacia de estos acuerdos y garantizar el reconocimiento y la ejecución de las sentencias dictadas en virtud de los mismos. Explica el organismo empresarial que la falta de un número mayor de ratificaciones, perjudica el comercio, pues las empresas necesitan mecanismos seguros de resolución de disputas transfronterizas. Dado que las empresas se enfrentan a dificultades para ejecutar sentencias extranjeras debido a legislaciones procesales nacionales contradictorias, esta Convención es una herramienta necesaria para la resolución efectiva de conflictos transfronterizos. El organismo gremial concluye que este instrumento tiene el potencial de lograr para los litigios judiciales lo que la Convención de Nueva York ha logrado para el arbitraje. ${ }^{113}$

La existencia de un régimen eficiente de acceso transnacional a la justicia aceptable eliminaría la posibilidad "primas de litigio" en las transacciones transfronterizas y reduciría el

\footnotetext{
${ }^{110}$ van Loon, Hans, The Global Horinzon of Private International Law, Inaugural Lecture, Private International Law Session, 2015, Offprint from Recueil des Cours, Brill nijhoff, Leiden/Boston, 2016, pp. 38-39.

${ }^{111}$ Véase, Espinar Vicente, José María, De lo tradicional y de lo nuevo en el Derecho Internacional Privado contemporáneo, en AAVV, Cursos de derecho internacional y relaciones internacionales, No. 1, 2010, pp. 273-322, esp. pp. 297-298.

${ }^{112}$ Strong, S.I., Recognition and Enforcement of Foreign Judgment..., ob. cit., 92-93.

${ }^{113}$ Véase comunicado de prensa de la CCI. Disponible en: https://iccwbo.org/media-wall/news-speeches/icc-callson-governments-to-facilitate-cross-border-litigation/. Consultado por última vez el 04/04/2018.
} 
costo de hacer negocios internacionalmente, ${ }^{114}$ permitiendo así a las empresas bajar los precios de los bienes y servicios de los consumidores estadounidenses. ${ }^{115}$

En un mundo donde las jurisdicciones estatales actúen coordinadamente facilitando el acceso transnacional a la justicia, los actores transnacionales procurarán ajustar su conducta y sus comportamientos estratégicos al cumplimiento de las normativas locales e internacionales. Mientras se vean en la posibilidad de evadir los alcances de las distintas jurisdicciones, sus comportamientos tenderán a evadir dicho cumplimiento, cuando esto les reporte ventajas económicas. ${ }^{116}$

La gobernanza judicial transnacional parecer ser un cajón de sastre. Pero, de nuevo, para bien o para mal, todo parecer indicar que los tribunales locales continuarán jugando un importante rol en la gobernanza global. ${ }^{117}$

\section{EL PRINCIPIO DE COOPERACIÓN JURÍDICA INTERNACIONAL. A MODO DE CONCLUSIÓN}

Una concepción del derecho de acceso transnacional la justicia en la que cada Estado pretenda garantizarlo aisladamente, sin el concierto de los otros, resulta totalmente contradictoria en sí misma. El ejercicio indiscriminado de una jurisdicción, por ejemplo, puede beneficiar de forma injustificada a una parte en perjuicio de la otra.

Se hace necesaria una idea de coordinación y cooperación internacional, que sustituya al paradigma de la plena separación recíproca de las soberanías. Esta circunstancia genera especiales desafíos para el análisis del acceso transnacional a la justicia y requiere enfoques más complejos que tomen en cuenta la eficiencia de la justicia, el equilibrio, la igualdad y el derecho a la defensa de todas las partes, así como la diversidad de las posibles situaciones que se plantean en función de los derechos cuya tutela se solicita. ${ }^{118}$

De esta manera, la idea de cooperación jurídica va mucho más allá de la "cooperación judicial internacional", también denominada "asistencia judicial internacional" o "cooperación internacional de autoridades". Estas figuras se refieren a los mecanismos procesales de asistencia entre los órganos judiciales o administrativos de los diversos Estados, para la realización de actos concretos relacionados a la función jurisdiccional; aluden a las actividades de asistencia recíproca de los Estados en la realización de sus funciones jurisdiccionales.

La noción de cooperación jurídica internacional, como principio, se refiere más bien al deber de colaboración internacional de los Estados para la realización de la justicia en general, como derecho humano esencial, lo que comprende todos los aspectos del proceso civil internacional, desde la determinación de la jurisdicción, la cooperación entre autoridades para la realización de actos jurídicos, la eficacia de las sentencias extranjeras (que es también una fórmula de cooperación entre autoridades), el tratamiento del litigante foráneo, el auxilio al arbitraje internacional, abarcando incluso la propia determinación de la ley aplicable. ${ }^{119}$ Esta

\footnotetext{
${ }^{114}$ Véase Grundfest, Joseph A. y Huang, Peter H., The Unexpected Value of Litigation: A Real Options Perspective, Stanford Law Review Vol. 58, 2006, pp. 1267-1335, esp. p. 1288. Disponible en: https://papers.ssrn.com/sol3/papers.cfm?abstract_id=899098. Consultado por última vez el 04/04/2018.

${ }^{115}$ Strong, S.I., Recognition and Enforcement of Foreign Judgments in U.S. Courts ..., ob. cit., p. 93.

${ }^{116} \mathrm{Al}$ respecto véase la conferencia de Pertegás, Marta: The Dutch-Russian Seminar on Legal Co-Operation, "Better Justice, Better Business". Disponible en: https://assets.hcch.net/docs/c8f6f762-7a14-464d-8103-0a3339c8d9c2.pdf ("It is evident that the lack of reliable and uniform rules in this area influences the decisions of companies and individuals regarding crossborder trade and foreign investment.") Consultado por última vez el 04/04//2018.

${ }^{117}$ Whytock, Christopher, Transnational Judicial Governance, ob. cit., p. 55.

${ }^{118}$ Fernández Arroyo, Diego P., La tendance à la limitation de la compétence judiciaire ..., ob. cit., pp. 285 ss.

${ }^{119}$ García Cano, Sandra, La Cooperación Internacional entre Autoridades en el Marco de la Protección del Menor en Derecho Internacional Privado Español, Tesis Doctoral, Córdoba, 2002, pp-. 23-25. Disponible en: http://helvia.uco.es/xmlui/bitstream/handle/10396/405/13208299.pdf?sequence=1. Consultado por última vez el 04/04/2018.
} 
noción envuelve también el deber de cooperar normativamente en la realización común de los fines de la justicia. ${ }^{120}$

Supone igualmente que el ejercicio de la actividad jurisdiccional, así como de las funciones administrativas que tengan incidencia en la dimensión jurídica de las personas, se lleve a cabo con actitud cooperativa, es decir, con la determinación de auxiliar y apoyar las funciones de las respectivas autoridades extranjeras en los asuntos jurídicos que atañen a las personas.

Para las relaciones jurídicas privadas el fundamento del principio de cooperación jurídica está reforzado desde la perspectiva constitucional, ${ }^{121}$ así como desde el Derecho Internacional de los Derechos Humanos. En el ámbito de las relaciones privadas transnacionales, la cooperación se convierte por antonomasia en la figura clave del acceso a la justicia. ${ }^{122}$

Del mismo modo, la ausencia de un principio de coordinación entre las jurisdicciones, pone en jaque las funciones de gobernanza global que pueden ejercer los tribunales.

En los TRANSJUS se consagró expresamente la idea de cooperación jurídica con el rango de principio general del proceso civil internacional, y como emanación simultánea de los valores de la gobernanza y de los derechos humanos, en especial, el derecho de acceso a la justica. Específicamente se alude a su objetivo de articular los poderes de los Estados en una relación de coordinación y cooperación para el logro de una justicia transnacional efectiva, lo que se considera un presupuesto necesario e impostergable para el bienestar social del planeta.

Esta idea encuentra desarrollo en varios de los principios establecidos. En especial el artículo 1.1.e, cuyo texto expresa:

Principio de cooperación jurídica internacional: El derecho de acceso a la justicia impone a todos los Estados y sus autoridades la obligación de cooperar jurídicamente en la realización de la justicia, más allá del plano meramente judicial, en cualquier situación que se vincule con jurisdicciones foráneas.

Dispuesto de esta forma se pretende que el principio sirva como guía en la elaboración e interpretación de las normas de cada sistema jurídico y, desde luego, al momento de integrar sus lagunas. En tal sentido, el principio debe adquirir un rol esencial en la actividad codificadora interna e internacional, y convertirse en el principio orientador de la interpretación, con un valor repotenciado que debería incluso desvirtuar o modificar el contenido de normas jurídicas positivas, cuando la aplicación de éstas menoscabe su realización. Cumpliría con una función hermenéutica esencial, con rango constitucional y de Derecho Internacional Público, que sugiere favorecer la cooperación entre los diferentes sistemas jurídicos. En la misma línea, los TRANSJUS establecen de manera expresa (art, 1.2) que en los litigios transnacionales la interpretación jurídica atenderá también al siguiente principio:

\footnotetext{
${ }^{120}$ Schlosser, Peter, Jurisdiction and International Judicial and Administrative Co-Operation, Offprintfrom the Collected Courses, Vol. 284, La Haya, 2000, p. 26.

${ }^{121}$ Véase, García Cano, Sandra, La cooperación internacional entre autoridades..., ob. cit., p. 11-13

122 Ochoa Muñoz, Javier, y Madrid Martínez, Claudia, Problemas de Acceso Transnacional a la Justicia en el Derecho Internacional Privado..., ob. cit., pp. 330-335.Soriano, Virgos y Garcimartín Alferez, Francisco,Derecho procesal civil internacional..., ob. cit., p. 41. En esta orientación, la Cumbre Judicial Iberoamericana en su reunión $\mathrm{N}^{\circ}$ XVII, llevada a cabo en abril de 2014, en Santiago de Chile, aprobó un importante instrumento denominado "Protocolo Iberoamericano sobre Cooperación Judicial Internacional", entre cuyas justificaciones se señala:

“... que garantizar el derecho de todas las personas a un recurso efectivo ante los tribunales para la protección de sus derechos fundamentales, así como el derecho a un debido proceso y el acceso a la justicia, consagrados en los más importantes instrumentos de derechos humanos, puede requerir de la intervención de órganos judiciales de distintos países, y que la falta de coordinación y cooperación entre los actores competentes del sistema judicial puede derivar precisamente en su vulneración.” en: http://www.cumbrejudicial.org/c/document library/get file?uuid=0db452e9-4509-43cb-bf2e$\underline{629 \mathrm{fa} 183 \mathrm{db} 53 \& \text { groupId=10124. }}$. Consultado por última vez el 04/04/2018.
} 
a.- Principio del "diálogo de fuentes" e interpretación conforme a los derechos humanos: Los jueces y demás operadores jurídicos interpretarán las normas substantivas y procesales no solo en función de su texto, sino atendiendo también a sus finalidades, teniendo en cuenta estos Principios y su coherente aplicación con los principios que informan el derecho internacional de los derechos humanos y los valores que inspiran la generalidad de las constituciones modernas. Las antinomias que pueda presentar esta diversidad de fuentes procurarán resolverse mediante una interpretación que las coordine y armonice en la medida de lo posible.

Para los TRANSJUS la cooperación jurídica internacional se erige no solo como un instrumento necesario para la protección de los derechos humanos en el plano transnacional, sino también como herramienta clave de la gobernanza global, contribuyendo a reforzar el rol del Estado, pero en una actuación que procure sustituir el paradigma de la soberanía para fundarse sobre el de coordinación. En esa coordinación no solo deben tenerse en cuenta las jurisdicciones estatales, sino también los sistemas jurisdiccionales internacionales, así como los sistemas internacionales y transnacionales de arbitraje, para engranarse armónicamente con los mismos, a fin de facilitar el acceso a la justicia en el orden global.

Los TRANSJUS se alinean en el doble desafío desafío del Derecho Internacional Privado a la luz de la globalización, que ha descrito muy bien Hans van Loon: eliminar los obstáculos obsoletos y locales a la actividad transnacional productiva, y proteger a las partes más débiles y los intereses públicos vitales, incluidos los bienes comunes, y así desempeñar su papel en la construcción de un futuro sostenible para la humanidad. ${ }^{123}$

Posiblemente descubriremos que hay mucho por mejorar en los TRANJUS. Una de las funciones de esta iniciativa es incentivar el trabajo doctrinario, y provocar la reflexión sobre temas que afectan a las personas. Desde ASADIP hemos dado un gran paso en ese sentido.

\section{REFERENCIAS}

Baumgartner, Samuel P., Transnational Litigation in the United States: The Emergence of a New Field of Law, American Journal of Comparative Law, Vol. 55, 2007. Disponible en: http://ssrn.com/abstract=1008355. Consultado por última vez el 04/04/2018.

Benvenisti, Eyal, The Law of Global Governance, Recueil des Courses, Collected Courses, Vol. $368,2014$.

Buxbaum, Hannah, Transnational Regulatory Litigation, Articles by Maurer Faculty, Paper 290, 2006. Disponible en en: http://www.repository.law.indiana.edu/facpub/290. Consultado por última vez el 01/03/2018.

Cançado Trindade, Antônio Augusto, Tratado de Direito Internacional dos Direitos Humanos, tomo III, Porto Alegre/Brasil, S.A. Fabris Ed., 2002.

Cappelletti, Mauro y Garth, Bryant, El acceso a la justicia. La tendencia en el movimiento mundial para hacer efectivos los derechos; trad. de Mónica Miranda, FCE, México, 1996.

Christopher A. Whytock, Domestic Courts and Global Governance: The Politics of Private International Law, Dissertation submitted in partial fulfillment of the requirements for the degree

${ }^{123}$ van Loom, Hans, The Global Horinzon of Private International Law, p. 26. Revista de Direito Brasileira | São Paulo, SP | v. 20 | n. 8 | p. 336-3363 |Mai./Ago. 2018 
of Doctor of Philosophy in the Department of Political Science in the Graduate School of Duke University, $2007 . \quad$ Disponible: en: https://dukespace.lib.duke.edu/dspace/bitstream/handle/10161/452/D_Whytock_Christopher_a_2 00712.pdf;sequence=. Consultado por última vez el 06/04/2018.

Ciro Milione, El derecho a la tutela judicial efectiva entre el Tribunal de Justicia de la Unión Europea y el Tribunal Europeo de Derechos Humanos. Disponible en: http://congresoace.deusto.es/wp-content/uploads/2016/01/Mesa-1-Ciro-Milione-BIS.pdf.

Consultada por última vez el 02/10/2017.

Espinar Vicente, José María, De lo tradicional y de lo nuevo en el Derecho Internacional Privado contemporáneo, en AAVV, Cursos de derecho internacional y relaciones internacionales, $\mathrm{N}^{\circ}$. 1, 2010.

Fernándes Arroyo, Diego P., La tendance à la limitation de la compétence judiciaire à l'épreuve du droit d'accès à la justice, en AAVV, Mélanges Bernard Audit, Dalloz, París, 2014.

Fernández Arroyo, Diego P., Argentina: Comentarios sobre el nuevo derecho internacional privado para la República Argentina. En: https://cartasblogatorias.com/2014/10/29/argentinaobservaciones-al-nuevo-dipr-para-la-republica-argentina/.

Fernández Arroyo, Diego P., Aspectos esenciales de la competencia judicial internacional en vistas de su reglamentación interamericana, en AAVV, Estudios de Derecho Internacional, Libro Homenaje al Profesor Santiago Benadava, T. II (Derecho internacional privado), Librotecnia, Santiago, 2008.

Fernández Arroyo, Diego, El Derecho internacional en el diván, Tribulaciones de un ser complejo, en AAVV, Derecho internacional privado y derecho de la integración, Libro Homenaje a Roberto Ruiz Díaz Labrano, CEDEP, Asunción, 2013.

Francesco Francioni, The Rights of Access to Justice under Customary International Law, en AAVV, Acces to Justice as a Human Right, Academy of Eropean Law, Eruropean University Institute y Oxford University Press, Nueva York, 2007.

Fresnedo de Aguirre, Cecilia, Public Policy: Common Principles in the American States, Recueil des Courses, Vol. 379, 2016.

García Cano, Sandra, La Cooperación Internacional entre Autoridades en el Marco de la Protección del Menor en Derecho Internacional Privado Español, Tesis Doctoral, Córdoba, 2002, pp-. 23-25. Disponible en: http://helvia.uco.es/xmlui/bitstream/handle/10396/405/13208299.pdf?sequence=1. Consultado por última vez el 04/04/2018.

Goicoechea, Ignacio, Nuevos Desarrollos en la Cooperación Jurídica Internacional en Materia Civil y Comercial, Revista de la Secretaria Permanente de Revisión, Año 4, No 7, Mayo 2016. Disponible en: http://www.revistastpr.com/index.php/rstpr/article/view/19. Consultado por última vez el 04/04/2018. 
Grundfest, Joseph A. y Huang, Peter H., The Unexpected Value of Litigation: A Real Options Perspective, Stanford Law Review Vol. 58, 2006. Disponible en: https://papers.ssrn.com/sol3/papers.cfm?abstract_id=899098. Consultado por última vez el 04/04/2018

Hongju Koh, Harold, Transnational Public Law Litigation, Yale Law Journal, Vo. 100, 199, pp. 2347-2402.

Disponible

en:

http://digitalcommons.law.yale.edu/cgi/viewcontent.cgi?article=2944\&context=fss_papers.

Kennedy, David, El misterio de la gobernanza global, Trad. M.A. Prada Uribe, Revista de $\begin{array}{llll}\text { Derecho } & \text { Público, } & \mathrm{N}^{\circ} & 24,\end{array}$ http://www.law.harvard.edu/faculty/dkennedy/publications/el\%20misterio\%20de\%20la\%20gobe rn_20100623113719.pdf. Consultado por última vez el 03/02/2018.

Klein Vieira, Luciane y Alvares Gaspar, Renata, Brasil: Habemus nuevo código procesal civil. Sus principales alteraciones en el derecho procesal internacional. En: https:/cartasblogatorias.com/2015/04/21/brasil-habemus-nuevo-codigo-procesal-civil-susprincipales-alteraciones-en-el-derecho-procesal-nternacional/. Consultado por última vez el 04/04/2018.

Mabarotto Lugaro, Jorge A., Un derecho humano esencial: el acceso a la justicia, Anuario de Derecho Constitucional Latinoamericano, Instituto de Investigaciones Jurídicas de la UNAM, 2003. En: http://www.juridicas.unam.mx/publica/librev/rev/dconstla/cont/2003/pr/pr16.pdf. Consultado por última vez el 04/04//2018.

Muir Watt, Horatia, Private International Law as Global Governance: Beyond the Schism, from Closet to Planet. Disponible en: http://works.bepress.com/horatia_muir-watt/1. Consultado por última vez el 03/04/2018.

Muir Watt, Horatia, Private International Law Beyond the Schism. Disponible en: https://spire.sciencespo.fr/hdl:/2441/53r60a8s3kup1vc9k70p9ikj1/resources/hmw-pilagg-paperfinal.pdf. Consultado por última vez el 06/04/2018.

Ochoa Muñoz, Javier L., La Cooperación Jurídica en el Siglo Actual, Desarrollo Histórico y Desafíos Actuales, en AAVV: Cuestiones Complejas en los Procesos de Restitución Internacional de Niños en Latinoamérica, Porrúa, Buenos Aires, 2017.

Ochoa Muñoz, Javier y Madrid Martínez, Claudia, Problemas de Acceso Transnacional a la Justicia en el Derecho Internacional Privado, Perspectiva Latinoamericana, en AAVV: Curso de Derecho Internacional, XLI, 2014, Comité Jurídico Interamericano, Organización de Estado Americanos, Washington, D.C., 2015.

Ortiz Ahlf, Loreta, El derecho de acceso a la justicia, en AAVV, Obra en homenaje a Rodolfo Cruz Miramontes. Tomo II. UNAM. México D.F., 200. Disponible en: https://archivos.juridicas.unam.mx/www/bjv/libros/6/2547/20.pdf. Consultado por última vez el 04/04/2018.

Perez, Antonio F., The International Recognition of Judgments: The Debate between Private and Public Law Solutions, Berkeley Journal of International Law, Volume 19, 2001. Disponible en: Revista de Direito Brasileira | São Paulo, SP | v. 20 | n. 8 | p. 336-3363 |Mai./Ago. 2018 
https://scholarship.law.berkeley.edu/cgi/viewcontent.cgi?article=1198\&context=bjil. Consultado por última vez el 04/04//2018.

Pertegás, Marta: The Dutch-Russian Seminar on Legal Co-Operation, "Better Justice, Better Business". Disponible en: https://assets.hcch.net/docs/c8f6f762-7a14-464d-81030a3339c8d9c2.pdf. Consultado por última vez el 04/04/2018.

Quintanilla, Marcus S. y Whytock, Christopher A., The New Multipolarity in Transnational Litigation: Foreign Courts, Foreign Judgments, and Foreign Law, Southwestern Journal of International Law, Vol.18, 2011.

Rábago Dorbecker, Miguel, El acceso a la justicia en casos de litigio internacional: foro de necesidad, asistencia judicial gratuita y cautio iudicato solvi. En AAVV, Anuario del Departamento de Derecho de la Universidad Iberoamericana, No 34, 2004.

Schlosser, Peter, Jurisdiction and International Judicial and Administrative Co-Operation, Offprint from the Collected Courses, Vol. 284, La Haya, 2000.

Sciso, Elena, Italian Judges' Point of View on Foreign States' Immunity, Vanderbilt Journal of Transnational Law, Vol. 44, 2011. Disponible en: https://www.vanderbilt.edu/wpcontent/uploads/sites/78/Scisco-pdf. Consultado por última vez el 04/04/2018.

Scotti, Luciana B., Los escenarios del Derecho Internacional Privado actual: Globalización, integración y multiculturalidad, en AAVV, Derecho internacional privado y derecho de la integración, Libro Homenaje a Roberto Ruiz Díaz Labrano, Asunción, CEDEP, 2013. Disponible también en: https://sociedip.files.wordpress.com/2013/12/los-escenarios-del-derechointernacional-privado-actual-globalizacic3b3n-integracic3b3n-y-multiculturalidad-scotti.pdf. Consultado por última vez el 04/04/2018.

Silberman, Linda, Transnational Litigation: Is There a "Field"? A Tribute to Hal Maier, Vanderbilt Journal of Transnational Law , Vol. 39, 2006, pp. 1427-1437. Disponible en: https://www.vanderbilt.edu/wp-content/uploads/sites/78/Silberman.pdf. Consultado por última vez el 04/04//2018.

Strong, S.I., General Principles of Procedural Law and Procedural Jus Cogens, 122 Penn State Law Review (2018 Forthcoming); 1 de Agosto 2017, University of Missouri School of Law Legal Studies Research Paper No. 2017-20. Disponible en: https://ssrn.com/abstract=3011947. Consultado por última vez el 04/04//2018.

Strong, S.I., Recognition and Enforcement of Foreign Judgments in U.S. Courts: Problems and Possibilities, Review of Litigation _ (forthcoming 2014), No. 33; University of Missouri School of Law Legal Studies Research Paper No. 2013-18. Disponible en: http://ssrn.com/abstract=2313855. Consultado por última vez el 04/04/2018.

Sykes, Alan O., Transnational Forum Shopping as a Trade and Investment Issue, Journal of Legal Studies, Vol. 37, 2008. Disponible en: https://www.law.virginia.edu/pdf/olin/0708/sykes.pdf. Consultado por última vez el 04/04//2018. 
van Loon, Hans, The Global Horinzon of Private International Law, Inaugural Lecture, Private International Law Session, 2015, Offprint from Recueil des Cours, Brill nijhoff, Leiden/Boston, 2016.

Wai, Robert, Transnational Liftoff And Juridical Touchdown: The Regulatory Function Of Private International Law In An Era Of Globalization, Columbia Journal of Transnational Law. Vol. 40, Tom.2, 2002.Disponible en: http://digitalcommons.osgoode.yorku.ca/cgi/viewcontent.cgi?article=1686\&context=scholarly_w orks. Consultado por última vez el 03/04/2018.

Whytock, Christopher A, Domestic Courts and Global Governance, Tulane Law Review, Vol. 84, No. 67, 2009. Disponible en: http://ssrn.com/abstract=923907. Consultado por última vez el $06 / 04 / 2018$.

Whytock, Christopher A. y Burke Robertson, Cassandra, Forum non conveniens and the enforcement of foreign judgments, Columbia Law Review, 2011, Vol. 111:144, pp. 1444 ss. El más reciente revés surgido para esta posibilidad fue la sentencia de la Corte Suprema de los Estados Unidos en el caso Kiobel vs. Shell 133 S.Ct. 1659 (2013).

Whytock, Christopher A., Faith and Scepticism in Private International Law: Trust, Governance, Politics, and Foreign Judgments, Erasmus Law Review, No. 3, Noviembre, 2014. Disponible en: http://ssrn.com/abstract=2549847. Consultado por última vez el 04/04//2018.

Whytock, Christopher A., Foreign State immunity and the right to court access, University of California, Irvine School of Law, Legal Studies Research Paper Series No. 2014-10, p. 2053.Disponible en: https://papers.ssrn.com/sol3/papers.cfm?abstract_id=2383372. Consultado por última vez el 04/04//2018.

Whytock, Christopher A., Transnational Judicial Governance, St. John's Journal of International \& Comparative Law, Vol. 2, 2012, pp 55-68, esp. p. 67. Disponible en: https://scholarship.law.uci.edu/cgi/viewcontent.cgi?article=1083\&context=faculty_scholarship. Consultado por última vez, el 18/03/2018.

Zeynalova, Yuliya, The Law on Recognition and Enforcement of Foreign Judgments: Is It Broken and How Do We Fix It?, Berkeley Journal of International Law, Nro. 31, 2013.Disponible en: http://scholarship.law.berkeley.edu/bjil/vol31/iss1/4. Consultado por última vez el 04/04/2018. 